\title{
Development and characterization of an in vitro alpha radiation exposure system for the purpose of cell culture
}

\author{
by \\ Lindsay Anne Beaton \\ B.Eng. in Engineering Physics, \\ Carleton University (2006)
}

\begin{abstract}
A thesis submitted to the Faculty of Graduate Studies and Research in partial fulfillment of the requirements for the degree of Master of Science
\end{abstract}

Ottawa-Carleton Institute of Physics

Department of Physics, Carleton University

Ottawa, Ontario, Canada

December, 2008

(c) Copyright 2008, Lindsay Beaton 


$\begin{array}{ll}\begin{array}{l}\text { Library and } \\ \text { Archives Canada }\end{array} & \begin{array}{l}\text { Bibliothèque et } \\ \text { Archives Canada }\end{array} \\ \begin{array}{l}\text { Published Heritage } \\ \text { Branch }\end{array} & \begin{array}{l}\text { Direction du } \\ \text { Patrimoine de l'édition }\end{array} \\ \begin{array}{l}\text { 395 Wellington Street } \\ \text { Ottawa ON K1A 0N4 } \\ \text { Canada }\end{array} & \begin{array}{l}\text { 395, rue Wellington } \\ \text { Ottawa ON K1A 0N4 } \\ \text { Canada }\end{array}\end{array}$

Your file Votre référence ISBN: 978-0-494-47532-4 Our file Notre référence ISBN: 978-0-494-47532-4

NOTICE:

The author has granted a nonexclusive license allowing Library and Archives Canada to reproduce, publish, archive, preserve, conserve, communicate to the public by telecommunication or on the Internet, loan, distribute and sell theses worldwide, for commercial or noncommercial purposes, in microform, paper, electronic and/or any other formats.

The author retains copyright ownership and moral rights in this thesis. Neither the thesis nor substantial extracts from it may be printed or otherwise reproduced without the author's permission.
AVIS:

L'auteur a accordé une licence non exclusive permettant à la Bibliothèque et Archives Canada de reproduire, publier, archiver, sauvegarder, conserver, transmettre au public par télécommunication ou par l'Internet, prêter, distribuer et vendre des thèses partout dans le monde, à des fins commerciales ou autres, sur support microforme, papier, électronique et/ou autres formats.

L'auteur conserve la propriété du droit d'auteur et des droits moraux qui protège cette thèse. $\mathrm{Ni}$ la thèse ni des extraits substantiels de celle-ci ne doivent être imprimés ou autrement reproduits sans son autorisation.
In compliance with the Canadian Privacy Act some supporting forms may have been removed from this thesis.

While these forms may be included in the document page count, their removal does not represent any loss of content from the thesis.
Conformément à la loi canadienne sur la protection de la vie privée, quelques formulaires secondaires ont été enlevés de cette thèse.

Bien que ces formulaires aient inclus dans la pagination, il n'y aura aucun contenu manquant.

\section{Canada}




\begin{abstract}
Radon gas $\left({ }^{222} \mathrm{Rn}\right)$, an alpha emitter, and its alpha emitting progeny are ubiquitous in our environment. Epidemiological studies have shown that the alpha radiation emitted by ${ }^{222} \mathrm{Rn}$ and its progeny is a significant source of background radiation and a leading cause of lung cancer. To study the biological effects of alpha radiation, an in vitro Alpha Radiation Exposure System (ARES) was designed. The ARES consisted of six ${ }^{241} \mathrm{Am}$ electroplated stainless steel discs with activities averaging $66 \mathrm{kBq}$ and Mylar-based culture Dishes (MD) to allow the transmission of alpha particles. The GEANT4 Monte Carlo simulation toolkit was used for the dosimetry calculations. The source code was adapted from the Microbeam example. The average dose-rate of the system was simulated to be $0.42 \pm 0.03 \mathrm{~Gy} \mathrm{hr}^{-1}$. The system was characterized by comparing the survival curves from gamma exposures on regular culture dishes to the MD, and then comparing the alpha exposure to the gamma exposure on the MD.
\end{abstract}




\section{ACKNOWLEDGEMENTS}

This thesis would not be what it is without the encouragement, support and advice of a great many people. I would like to sincerely thank:

- Dr. Ruth Wilkins, for being an excellent supervisor, professor, and for being a personal and professional inspiration.

- Dr. Trevor Stocki, for first introducing me to Monte Carlo (EGSnrc) and from there sparking my interest in Medical Physics.

- Dr. Sami Qutob, Sylvie Lachapelle, Barbara Kutzner and Catherine Ferrarotto, Dr. Vinita Chauhan and Shifawn O'Hara, Dr. David Michaud and Dr. James McNamee, my colleagues in the lab (Consumer and Clinical Radiation Protection Bureau, Health Canada), for answering my questions and making the lab such a great place to work.

- Professors Paul Johns, Dave Rogers, and Dave Wilkins, for being extraordinary teachers. Their time and energies have made Medical Physics an exciting field to study.

- Maria Grazia Pia (INFN Genova), Anton Lechner (Vienna University of Technology) and Luciano Pandola (INFN Gran Sasso National Laboratory), for running a fantastic GEANT4 Introductory course at Oak Ridge National Laboratory (May 2008).

- Joanne and Alex McAuley, who have been with me from the beginning of my thesis, for being the best friends and roommates, always good for a laugh over dinner and board games. Special thanks to Alex for turning my sketch into Figure 2-3.

- Elena Gil, Katherine Taylor, Annie Kelly and Scott Miller, my dearest friends.

- My family; Mark, Evelyn, Jill and Dale Beaton, for always giving me a loving home full of unlimited encouragement and enthusiasm.

- Chris Green, mo cridhe, simply for being the best. 


\section{TABLE OF CONTENTS}

ABSTRACT ii

ACKNOWLEDGEMENTS iii

TABLE OF CONTENTS iv

LIST OF ABBREVIATIONS vii

LIST OF FIGURES $\quad$ ix

LIST OF TABLES $\quad$ xi

CHAPTER 1. INTRODUCTION

1.1 Radon 1

1.2 Alpha Particles 3

1.2.1 Stopping Powers and Linear Energy Transfer 5

$\begin{array}{lll}1.3 & \text { Health and Biological Effects } & 7\end{array}$

1.4 Effects of Radiation and Types of Cell Death 10

1.4.1 Mechanisms of Cell Kill 10

$\begin{array}{lll}1.4 .2 & \text { DNA Strand Breaks } & 10\end{array}$

$\begin{array}{lll}1.5 & \text { Growth Curves } & 13\end{array}$

$\begin{array}{lll}1.6 & \text { Cell Survival } & 13\end{array}$

1.6.1 Definition of Cell Survival 13

$\begin{array}{ll}\text { 1.6.2 Survival Curves } & 14\end{array}$

1.6.3 Relative Biologic Effectiveness of Alpha and X Radiations 17

1.7 Dosimetry 19

1.7.1 The Measurement of Energy Deposited by Radiation: 19

$\begin{array}{lll}\text { 1.7.2 Monte Carlo Method } & 19\end{array}$

$\begin{array}{lll}1.7 .3 & \text { SRIM2008 } 20\end{array}$

$\begin{array}{lll}\text { 1.7.4 GEANT4 } & 21\end{array}$

1.7.5 GEANT4 Simulation Details 22

1.8 Existing Alpha Radiation Exposure Methods 24

1.9 Hypothesis 25

CHAPTER 2. MATERIALS AND METHODS 27 
$\begin{array}{llr}2.1 & \text { Sources } & 27\end{array}$

2.1.1 Gamma Source 27

2.1.2 Alpha Sources 27

2.2 Dishes 32

$\begin{array}{lll}2.2 .1 & \text { Collagen } & 37\end{array}$

2.3 Cell Culture 37

2.3.1 Trypsin and Cell Count 38

2.3.2 Growth Curves 39

2.4 Clonogenic Assay 41

$\begin{array}{lll}2.4 .1 & \text { Irradiation } & 41\end{array}$

$\begin{array}{lll}2.4 .2 & \text { Plating } & 42\end{array}$

2.4.3 Staining, Washing and Counting 43

2.5 Dosimetry 45

$\begin{array}{lll}2.5 .1 & \text { SRIM2008 } & 45\end{array}$

$\begin{array}{lll}2.5 .2 & \text { GEANT4 } & 45\end{array}$

2.5.3 Detector Constructor (DC) 46

2.5.4 Physics List (PL) 48

2.5.5 Primary Generator 49

2.5.6 Run, Event, and Stepping Actions 50

$\begin{array}{lll}2.5 .7 & \text { Output } & 51\end{array}$

CHAPTER 3. RESULTS 53

3.1 Sources 53

3.1.1 Alpha Sources 53

3.2 Dishes 53

3.2.1 Transmission of Alpha Particles 53

3.2.2 Sterilization and Cell Culture 55

$\begin{array}{lll}3.3 & \text { Dosimetry } & 61\end{array}$

3.4 Survival Curves $\quad 65$

$\begin{array}{lll}\text { CHAPTER 4. DISCUSSION } & 71\end{array}$ 
4.1 Sources 71

$\begin{array}{lll}\text { 4.1.1 Energy of the Sources } & 71\end{array}$

4.1.2 Radioactive Decay over Time 71

$\begin{array}{ll}\text { 4.1.3 Protecting the Sources } & 71\end{array}$

4.2 Dishes 73

$\begin{array}{lll}4.2 .1 & \text { Fabrication } & 73\end{array}$

$\begin{array}{lll}4.2 .2 \text { Cost } & 73\end{array}$

$\begin{array}{lll}\text { 4.2.3 Attenuation and Build-up } & 74\end{array}$

4.3 Cell Lines 74

4.3.1 Use of Immortalized Cells or Primary Cells 74

4.3.2 Use of Adherent Cells or Suspension Cells 74

4.4 Dosimetry 76

4.4.1 Monte Carlo Model 76

4.4.2 Alpha Particle Range $\quad 77$

$\begin{array}{lll}\text { 4.4.3 Dose Rate } & 78\end{array}$

$\begin{array}{lll}4.5 & \text { Cell Damage } & 79\end{array}$

$\begin{array}{lll}\text { CHAPTER 5. CONCLUSION } & 81\end{array}$

5.1 Functioning Alpha Exposure System 81

5.2 Future Research 82

CHAPTER 6. REFERENCES 83

$\begin{array}{ll}\text { APPENDIX A } & 89\end{array}$ 


\section{LIST OF ABBREVIATIONS}

A-549 Lung cancer cell line (carcinoma)

ARES Alpha Radiation Exposure System

ARS Acute Radiation Syndrome

CENBG Le Centre d'Etudes Nucléaires de Bordeaux Gradignan

CERN Conseil Européen pour la Recherche Nucléaire

CSDA Continuous Slowing Down Approximation

D

Absorbed Dose (Gy)

DC Detector Constructor

DNA DeoxyriboNucleic Acid

DSB Double Strand Break

EDTA EthyleneDiamineTetraacetic Acid

ESA European Space Agency

FBS Fetal Bovine Serum

GEANT4 GEometry ANd Tracking toolkit

HEP High Energy Physics

ICRP International Commission of Radiological Protection

LET Linear Energy Transfer

LQ Linear Quadratic

LV Logical Volume

MB MicroBeam

MC Monte Carlo

MD Mylar Dish

NIST National Institute of Standards and Technology

PBS Phosphate Buffered Saline

PE Plating Efficiency

PG Primary Generator

PL Physics List 


\begin{tabular}{ll} 
PV & Physical Volume \\
RBE & Relative Biologic Effectiveness \\
S & Mass stopping power \\
SA & Surface Area \\
SD & Seeding Density \\
SE & Surface Emission \\
Sion & Ionizational stopping power \\
S $r a d$ & Radiative stopping power \\
SF & Surviving Fraction \\
SLAC & Stanford Linear Accelerator Center \\
SRIM & Stopping Range of Ions in Matter software \\
SSB & Single Strand Break \\
SV & Solid Volume \\
t $1 / 2$ & Half-life \\
T25 & A plastic cell culture flask with a surface area of $25 \mathrm{~cm}^{2}$ \\
T75 & A plastic cell culture flask with a surface area of $75 \mathrm{~cm}^{2}$ \\
U87-MG & Brain cancer cell line (glioblastoma) \\
v/v & Volume per volume \\
w/v & Weight per volume \\
& \\
\hline
\end{tabular}




\section{LIST OF FIGURES}

Figure 1-1: Illustration of the uranium-radium decay series

Figure 1-2: The sequence of effects from the interaction of radiation with

matter.

Figure 1-3: $\quad$ Single and double strand breaks (SSB and DSB) in a DNA strand. 12

Figure 1-4: Typical survival curves for high and low LET radiation. ................16

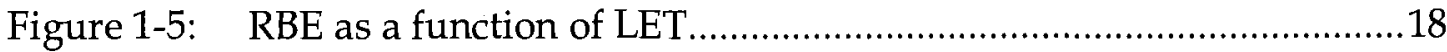

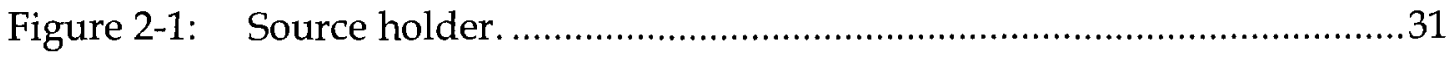

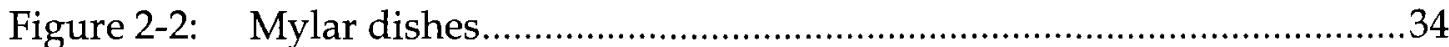

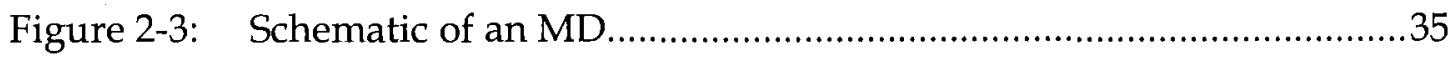

Figure 2-4: Adapted class diagram illustrating the dependent classes used in

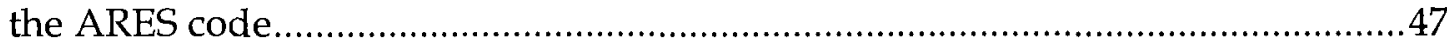

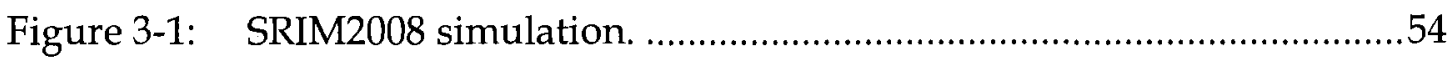

Figure 3-2: Growth Curve of U87-MG cells on 6WP and MDs, with and without collagen.

Figure 3-3: Growth Curve of U87-MG cells on 6WP and MDs, at different seeding densities.

Figure 3-4: Growth Curve of A-549 cells on 6WP and MDs, with and without collagen

Figure 3-5: Growth Curve of A-549 cells on 6WP and MDs, at different seeding densities. 60

Figure 3-6: Three dimensional scatter plot of the initial trajectories of $1 \%$ of the alpha particles.

Figure 3-7: Survival curves, fit by LQ model, of gamma irradiation of A-549 cells in confluent T25s and confluent MDs. .66 Figure 3-8: Survival curves, fit by LQ model, of gamma and alpha irradiation of A-549s in confluent MDs. 
Figure 3-9: Survival curves, fit by LQ model, of gamma and alpha irradiation of A-549s in confluent MDs. The fit of the alpha irradiated dishes was done in two parts, with the last three data points fit to the adjusted LQ model .................68 Figure 3-10: Alpha and gamma survival curves with drop lines illustrating the dose points used for the RBE calculation. 


\section{LIST OF TABLES}

Table 2-1: Americium alpha energies and their emission probabilities, for

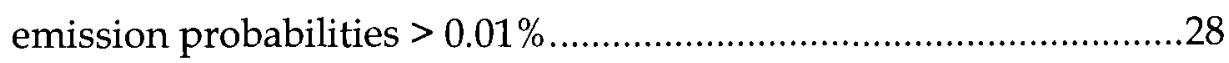

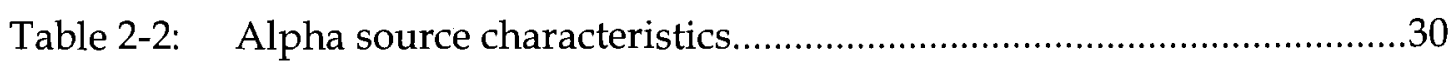

Table 2-3: Dish materials and thicknesses for both the T25 and MD................36

Table 2-4: Stopping range of $5.48 \mathrm{MeV}$ alpha particles through various

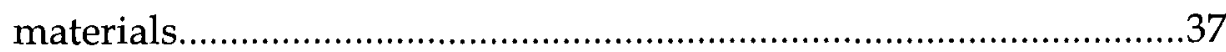

Table 2-5: Coulter counter settings for cell types U87-MG and A-549..............39

Table 2-6: Seeding densities used for each of six growth curves........................40

Table 2-7: Plating numbers for alpha and gamma irradiation of A-549 cells....43

Table 2-8: Solid, logical and physical volume details for the volumes described by the ARES model ............................................................48

Table 3-1: Conversion of the time of exposure to an absorbed dose.................62

Table 3-2: Comparison of dose rates between the different ${ }^{241} \mathrm{Am}$ discs ...........63

Table 3-3: Alpha and beta values from the fits of Figures 3-7 to 3-9 ...............70 


\section{CHAPTER 1. INTRODUCTION}

\subsection{Radon}

Radon gas (222 Rn) and its progeny are high energy alpha particle emitters which are found naturally in our environment. ${ }^{222} \mathrm{Rn}$ is part of a serial transformation chain, where its progeny also undergo radioactive decay [1]. It has a half life of 3.825 days and it decays $99.92 \%$ of the time by emission of an alpha particle with an energy of $5.49 \mathrm{MeV}$ [2]. ${ }^{222} \mathrm{Rn}$ is the progeny of the long lived uranium isotope, ${ }^{238} \mathrm{U}$, which is found throughout the earth. Figure 1-1 contains the half-lives and the energies of the alpha emitting isotopes involved in the serial decay of ${ }^{222} \mathrm{Rn}$.

Two of the radioactive progeny of ${ }^{222} \mathrm{Rn}$ are ${ }^{218} \mathrm{Po}$ and ${ }^{214} \mathrm{Po}$, both alpha emitters. These polonium isotopes are also charged particles that can become attached to aerosols which can be deposited in the lungs. With half lives of 3.05 minutes and $160 \mu \mathrm{s}$, the polonium isotopes each emit a subsequent alpha particle as they decay, with respective energies as high as $6.00 \mathrm{MeV}$ and 7.69 MeV (Figure 1-1). The International Commission on Radiological Protection (ICRP) estimated that the combined external and internal exposure to ${ }^{222} \mathrm{Rn}$ gas and its progeny contributes approximately half $(52 \%)$ of the background radiation that the public is exposed to in a given year [3]. 


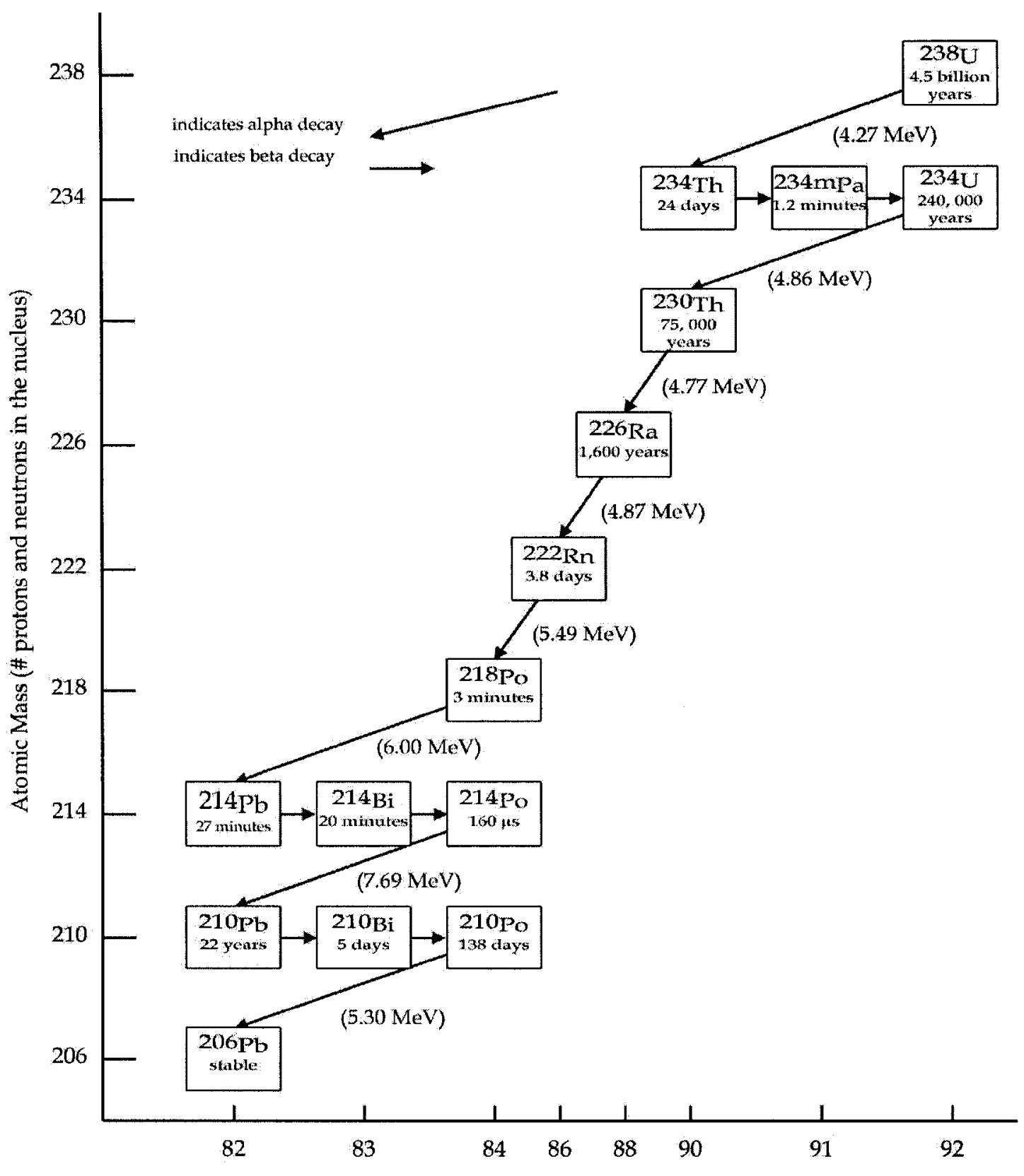

Atomic Number (\# protons in the nucleus)

Figure 1-1: Illustration of the uranium-radium decay series: ${ }^{222} \mathrm{Rn}$ is a part of the ${ }^{238} \mathrm{U}$ serial decay chain. From ${ }^{222} \mathrm{Rn}$ to the final stable lead isotope, four alpha particles are emitted with energies up to 7.69 $\mathrm{MeV}$. The highest alpha particle energies are listed (in MeV) along with the half-lives of each isotope. The beta and gamma emissions are omitted [2]. Note that the $x$-axis is compressed in the middle (for atomic numbers 84 to 90 ). 
As an inert noble gas, ${ }^{222} \mathrm{Rn}$ easily travels through rocks and soil to the surface of the earth and although the outdoor concentration of ${ }^{222} \mathrm{Rn}$ is very dilute (on the order of $10 \mathrm{~Bq} \mathrm{~m}^{-3}$ measured $2.5 \mathrm{~m}$ above the ground [4]), the gas can enter homes by means of cracks in the foundation, exposed soil and rock, and improperly sealed pipes [5]. Without proper ventilation, the concentration of ${ }^{222} \mathrm{Rn}$ can build up to hazardous levels. A metastudy of North American case studies by D. Krewski et al [6] found that highest mean concentrations reached 131.1 Bq $\cdot \mathrm{m}^{-3}$, while the lowest concentrations were $25.1 \mathrm{~Bq} \cdot \mathrm{m}^{-3}$. A collection of European studies analyzed by S. Darby et al. [7] found that the risk of lung cancer increased by $8 \%$ per $100 \mathrm{~Bq} \mathrm{~m}^{-3}$ and that exposure to ${ }^{222} \mathrm{Rn}$ was responsible for approximately $9 \%$ of deaths from lung cancer and $2 \%$ of all deaths from cancer in Europe [7]. The determination of increased risk is a highly debated issue since at low doses and low dose rates, the historical radiobiological data is less defined and more open to interpretation than at higher doses. Regardless, there is a correlation between exposure to radon and increased incidence of lung cancer [6;7]. Preliminary studies in Canada have shown that a number of residential homes have concentrations measuring higher than the recently adopted 200 $\mathrm{Bq} \mathrm{m}^{-3}$ Canadian guideline limit $[8 ; 9]$ leading to a renewed interest in the health effects of ${ }^{222} \mathrm{Rn}$ exposure. ${ }^{222} \mathrm{Rn}$ can also be found dissolved in the ground water, which then also contributes to the dose to internal organs $[10 ; 11]$.

\subsection{Alpha Particles}

Alpha radiation occurs predominantly in heavy nuclei. It is one of the principle decay mechanisms of the long lived radioisotope series, which prefer to transition to more stable isotopes along the line of stability in the chart of the nuclides [12]. The general equation for the reaction is given by Equation 1: 


$$
{ }_{Z}^{A} X \rightarrow{ }_{Z-2}^{A-4} Y+\alpha+2 e^{-}+Q
$$

\section{Equation 1}

Where: $\quad A=$ mass number,

$\mathrm{Z}=$ atomic number,

$\mathrm{X}=$ parent isotope,

$\mathrm{Y}=$ progeny,

$Q=$ the kinetic energy released by the reaction.

Classically, the alpha particle does not have enough energy to escape the potential well of the nucleus, but with quantum mechanics, there is a probability that the alpha particle might tunnel through the Coulomb barrier and escape the nucleus [13]. The disintegration constant, $\lambda$, is therefore the product of the frequency, $f$, with which the alpha particle presents itself at the Coulomb barrier, and the probability, $P$, for transmission through the barrier, as shown in Equation 2.

$$
\lambda=f P
$$

Equation 2

Alpha particles, shown by Rutherford in 1909 to be helium nuclei, are characterized as having a large kinetic energy, but a very straight, short range due to their relatively large mass compared to other particles emitted by radioactive decay. Characteristically, the alpha particle carries away about $98 \%$ of the kinetic energy from the reaction [13]. They are essentially monoenergetic, and have straight trajectories [14]; therefore the mean range of an alpha particle trajectory is very close to the maximum extrapolated range. As the least penetrating form of radiation, alpha particles are easily stopped by most materials, travelling only a few micrometers in tissue and a few centimeters in air [12]. The most important mechanism for the energy loss of the alpha particle is interaction between the alpha particle and the absorbing medium's electrons. 
The passage of an alpha particle through a medium results in the creation of many thousands of ion pairs [1].

\subsubsection{Stopping Powers and Linear Energy Transfer}

The interactions of the electric field of a charged particle, such as an alpha particle, with the electric field of an electron in a medium result in the loss of kinetic energy of the alpha particle. The mass stopping power, $\mathrm{S}$, of a medium describes the energy loss per unit thickness of a medium measured in $\mathrm{g} \mathrm{cm}^{-2}$ (Equation 3).

$$
S=\frac{1}{\rho} \frac{d E}{d x}
$$

\section{Equation 3}

Where: $\quad \frac{d E}{d x}=$ energy loss per unit thickness of medium of density $\rho$.

Stopping Power is made up of the contributions of two types of stopping power, radiative $\left(S_{\text {rad }}\right)$ and ionizational $\left(S_{\text {ion }}\right)$. The $S_{\text {rad }}$ term is a dominant contribution in high $\mathrm{Z}$ materials for light particles such as electrons. For heavier particles, such as alpha particles or heavy ions, the $S_{\text {rad }}$ contribution is negligible [12]. $S_{\text {ion }}$ is given by the Bethe-Bloch equation (Equation 4):

$$
S_{\text {ion }}=4 \pi r_{0}^{2} N_{e} \frac{z^{2} m_{0} c^{2}}{\beta^{2}}\left[\ln \frac{2 m_{0} c^{2} \beta^{2}}{I\left(1-\beta^{2}\right)}-\beta^{2}-\sum_{i} \frac{c_{i}}{Z}\right]
$$

\section{Equation 4}

Where: $\quad r_{o}=$ classical electron radius,

$N_{e}=$ number of electrons per gram of material,

$Z=$ atomic number of material

$Z=$ atomic number of the incident particle 


$$
\begin{aligned}
& m_{0}=\text { rest mass of an electron } \\
& c=\text { speed of light } \\
& \beta=\text { relativistic energy of the incident particle } \\
& I=\text { average excitation energy } \\
& c_{i}=\text { shell correction }
\end{aligned}
$$

There is a small dependence upon the irradiated medium, from the average excitation energy and shell correction factors. At relativistic energies, there is also a slight increase in $S_{\text {ion. }}$ Otherwise, $S_{\text {ion }}$ depends most strongly upon the term $\frac{z^{2}}{\beta^{2}}$, and so for alpha particles, with $\mathrm{z}=2$, the stopping power is large in comparison to protons.

A critical characteristic of alpha particles is their high linear energy transfer (LET) values. Similar to $S$, LET is a measure of the ionization along a radiation track; it is defined as the energy deposited per unit length of the particle track and is generally given in units of $\mathrm{keV} \cdot \mu \mathrm{m}^{-1}$. However, unlike S, LET does not include the kinetic energy carried away by secondary electrons as delta rays. Typical LET values for $250-\mathrm{kV}$ x-rays are $2.0 \mathrm{keV} \cdot \mu \mathrm{m}^{-1}$ while $2.5 \mathrm{MeV}$ alpha particles have an LET of $166 \mathrm{keV} \mu \mathrm{m}^{-1}$ [12]. High LET alpha particles create a very dense ionizing track as they traverse a medium. Therefore, they produce more significant biological effects when compared to equivalent doses from low LET radiation, which are more sparsely ionizing [1;12]. 


\subsection{Health and Biological Effects}

In terms of a health hazard, the outer layer of skin is commonly accepted as sufficient protection from alpha particles [1]. Nonetheless, if ingested or inhaled, radionuclides which emit alpha particles may cause significant damage to sensitive internal human tissue [11]. The biological effects of ingestion of an alpha particle emitter, such as ${ }^{210} \mathrm{Po}$, has been studied [15;16] and although cases of ingested alpha emitters are few, a recent incident became the subject of high profile media attention. On November 1, 2006 [17], Alexander Litvinenko was poisoned with ${ }^{210} \mathrm{Po}$, which emits $5.298 \mathrm{MeV}$ alpha particles and has a half-life of 138.4 days. Within the span of only a few weeks, Litvinenko showed symptoms of acute radiation syndrome (ARS) including gastrointestinal syndrome which is a form of prodromal syndrome, with flu-like nausea, vomiting and easy fatigability. As expected, after high doses of radiation, hematopoietic syndrome symptoms showed up within weeks, as the radiation sterilized critical cells [18]. The estimated activity of the dose he received was 2 GBq, an activity roughly 200 times that of the mean lethal activity of about $10 \mathrm{MBq}$. He died on November $23^{\text {rd }}, 2006$ [17].

Epidemiological studies conducted in both European [7] and North American homes [6;9] have shown a need for further study of the biological effects resulting from the inhalation of alpha particle emitters such as ${ }^{222} \mathrm{Rn}$. Most of the ${ }^{222} \mathrm{Rn}$ progeny are deposited in the upper respiratory tract between the trachea and the terminal bronchioles [1]. Alpha particles emitted in this area are deposited in the epithelial cells of the lungs. ${ }^{222} \mathrm{Rn}$ which comes into equilibrium with the gas in human lungs can penetrate further into the alveoli, where gas exchange takes place between the lungs and the blood. The gas must only penetrate two cell layers (the capillary wall and the alveolar wall) in order to get into the blood stream [1]. The equivalent annual dose to the bronchial epithelium from alpha particles may be up to 90 times higher than that from environmental 
gamma radiation, when quality factors are taken into account [19]. This would explain why epidemiological studies have shown an increased risk of developing lung cancer with increased exposure to radon gas.

The interaction of radiation with matter is illustrated by Figure 1-2. The physical interactions, occur as the radiation enters a biological system and primary and secondary interactions that take place result in ionization, excitation and subsequently the breaking of chemical bonds and the generation of heat. The broken chemical bonds can lead to chemical changes within critical sites in the cells. This can lead to biological damage such as cell death or mutation. It is important to study the radiobiological effects to further understand the short and long term repercussions of this type of biological damage. 


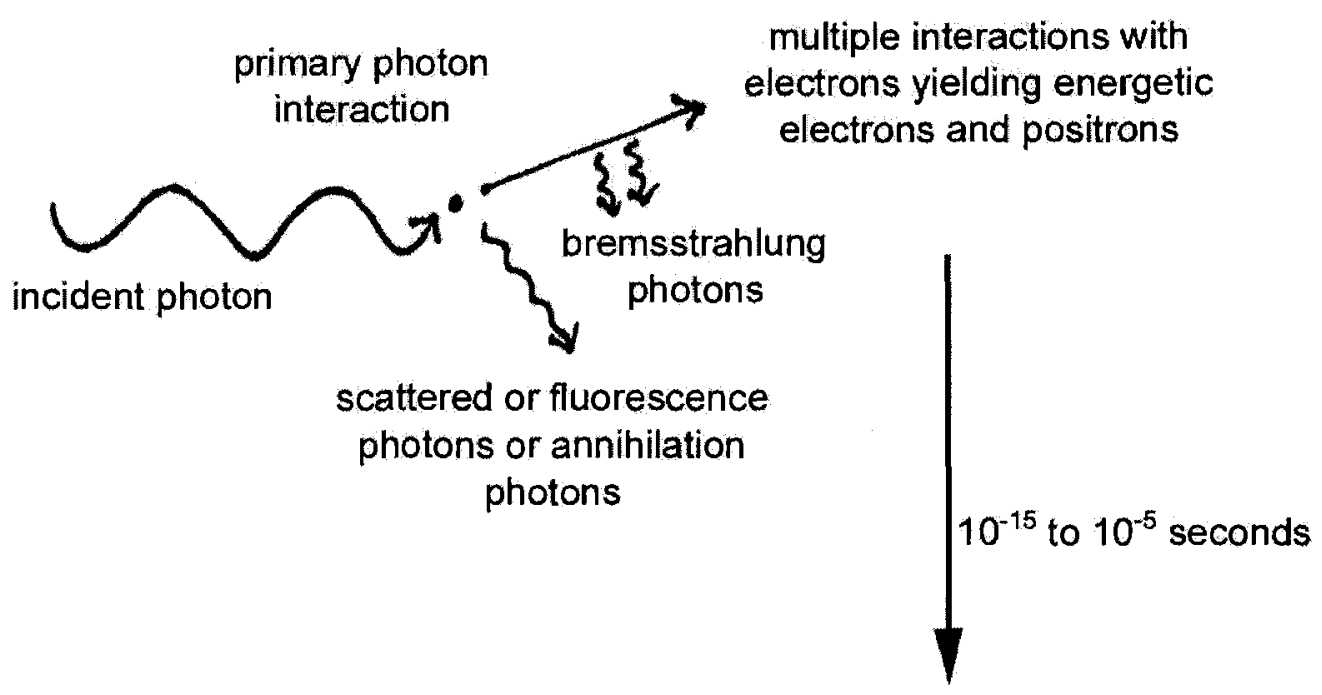

broken chemical bonds

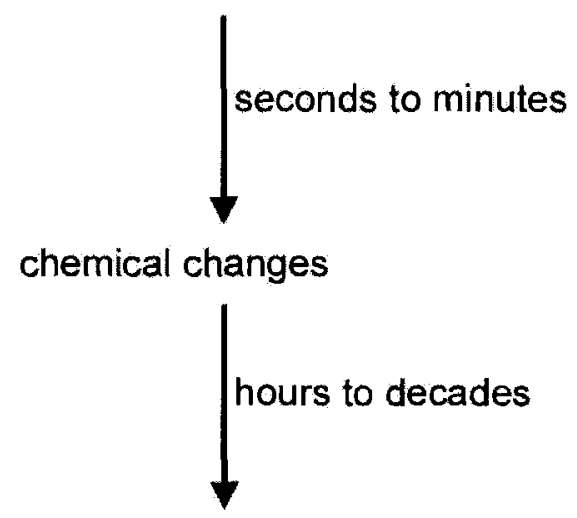

biological changes

Figure 1-2: The sequence of effects from the interaction of radiation with matter. The physics of the early processes are very well understood, while the chemical changes and subsequent biological damage have many confounding factors [12]. 


\subsection{Effects of Radiation and Types of Cell Death}

\subsubsection{Mechanisms of Cell Kill}

The main target for radiation damage in the cell is the DNA. There are two types of action that cause damage to the DNA, direct and indirect action. Direct action occurs when the radiative particle interacts with the DNA molecule. Indirect action occurs when the radiation interacts with other molecules, such as water in the cell, producing free radicals which then damage the DNA strand [20]. HighLET radiation, such as alpha particles, is more likely to produce direct action, whereas exposure to gamma radiation results in more indirect action.

\subsubsection{DNA Strand Breaks}

The DNA molecule is a large double helix structure, made up of two long strands held together by hydrogen bonds. The strands are made of sugar and phosphate groups, to which four base pairs, adenine, cytosine, thymine and guanine, are attached. The structure of these base pairs is unique, and bases on opposite strands must be complementary; adenine to thymine and cytosine to guanine. The unique sequences of these base pairs form the genetic material inherent to living organisms. When one of the strands is damaged, a single strand break (SSB) is formed and there exist mechanisms to repair the strand based upon the structure of the opposite strand. However, if both strands are broken in close proximity, forming a double strand break (DSB), either from a single radiation event (mode 1) or two independent events which occur close together in time and location (mode 2), the damage is understood to be critical [18] (Figure 1-3).

The number of DSB is increased when the dose is increased, due to a higher likelihood of SSB interactions occurring close together in space (mode 2). Furthermore, with high LET radiation, the DSB are more likely to occur from one 
radiation track (mode 1), when the interaction track length is similar to the spacing of the double helix strands.

Response to the DNA damage may result in one of three processes: DNA repair, cell death or DNA mutation. When the DNA is correctly repaired, there are no biological implications with respect to cell death. Furthermore, cell death, defined as the loss of cell function or reproductive capabilities, has few implications if the number of cells killed is low, although there are more serious implications with increasing number of cells killed [18]. If enough cells are killed, there will be a loss of function on a larger scale. Thus, Acute Radiation Syndrome (ARS) occurs at high doses when penetrating radiation is able to reach and seriously damage internal organs. For example, at doses between 2.5 and 5 Gy, damage to stem cells in the bone marrow results in hematopoietic syndrome. At higher doses, between 5 and $12 \mathrm{~Gy}$, radiation damages critical dividing cells within the epithelial lining in the gastrointestinal tract. Known as gastrointestinal syndrome, this type of damage is lethal, leading to death within days. However, with incorrect repair, DNA mutation can occur and the cell is not killed, but the mutated cell may lead to cancerous tumours, with very serious implications [18].

While the physical interactions of the radiative processes take place in fractions of a second, the repercussions of the biological changes can take years to manifest [20]. DNA repair mechanisms take place on the order of hours. If enough cells are killed and biological functions are lost, as in the case of ARS, the results are noticeable within days to a few weeks. Cell mutations can take years to present, and cancerous tumours can grow for years before being diagnosed [21]. 
12
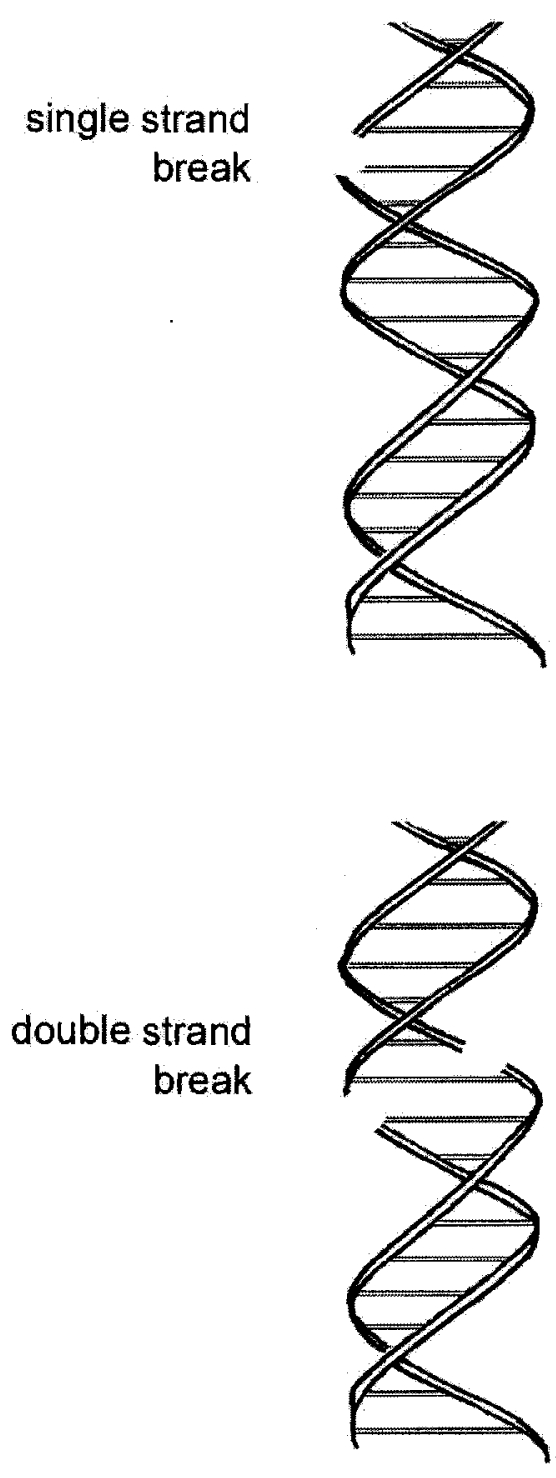

Figure 1-3: Single and double strand breaks (SSB and DSB) in a DNA strand. 


\subsection{Growth Curves}

A cell line, subcultured routinely, will go through a growth pattern characteristic of each cell line. There are three phases to this growth pattern; the lag phase, the $\log$ phase, and the plateau phase. The initial lag phase is a relatively short period which occurs just after subculture, where the cells adjust to their changed environment. During this phase, there is little to no increase in the number of cells. Once the cells have readjusted to the environment, the cell population will enter a phase of exponential growth, known as the log phase. The cell population is most active during this phase, and it is the optimum time to perform experiments. Lastly, the cell population reaches the plateau phase, where the cell density has reached a maximum, most of the growing surface has been covered by cell growth and the cell growth slows dramatically [22].

\subsection{Cell Survival}

\subsubsection{Definition of Cell Survival}

Cell death can be defined by various standards. Apoptosis is known as programmed cell death where the cell eventually breaks apart into small fragments, known as apoptotic bodies which are subsequently absorbed by neighbouring cells [18]. Another form of cell death is mitotic death, where a damaged cell's attempt to divide fails due to damaged chromosomes. A damaged cell might not necessarily disappear, but if it has lost its reproductive integrity, then it is considered to have died [18].

The definition of cell survival depends upon the context of interest. For in vitro experiments, the measured quantity of interest is the loss of reproductive integrity, or the loss of the capacity for sustained proliferation of a cell [23]. The term clonogenic survival is used when referring to cells which maintain the 
ability to multiply into macroscopic colonies, by definition, containing 50 or more normal cells.

\subsubsection{Survival Curves}

A survival curve is described by plotting the surviving fraction (SF) of cells as a function of dose. A clonogenic assay is essentially a method with which to measure the clonogenic survival of irradiated cells in vitro. After irradiation, a small fraction of the irradiated cells are placed in a nutrient medium and incubated for a few weeks; the surviving cells will form colonies which can be visualized and counted, while the inactivated cells fail to form these colonies of over 50 cells [24]. Note that as the dose is increased, the fraction of irradiated cells required for approximately the same number of colonies, also increases. The SF is calculated from Equation 5:

$$
S F=\frac{\text { Colonies counted }}{\text { Cells plated } \cdot\left(\frac{P E}{100}\right)}
$$

\section{Equation 5}

Where: $\quad P E=$ plating efficiency $(\%)$

Plating efficiency (PE) is a measure of the number of cells that grow into colonies from a sample of cells that have not been irradiated. This gives an indication of how many cells survive under reference conditions. Optimally, $100 \%$ of cells should survive if they have not been irradiated, but there are a few biological factors, including trauma from trypsinization and cell culture work, which effect cell growth. PE is calculated from Equation 6.

$$
P E=\frac{\text { Number of colonies counted }}{\text { Number of cells plated }} \cdot 100 \% \quad \text { Equation } 6
$$


The linear-quadratic (LQ) model, derived by Chadwick and Leenhouts [25] is the generally accepted model for the shape of the survival curve [26]. The equation for fitting cell survival fraction (SF) for this model is given by Equation 7 .

$$
S F=e^{-\alpha D-\beta D^{2}}
$$

\section{Equation 7}

Where: $\quad \mathrm{D}=$ absorbed dose

$$
\alpha, \beta=\text { constants }
$$

The constants $\alpha$ and $\beta$ are related to the damage caused and unrepaired by modes 1 and 2, respectively. The $\alpha$ term will dominate when mode 1 (DSB resulting from 1 radiation event) accounts for most of the radiation damage. The likelihood of 1 radiation event breaking both DNA strands increases with increasing LET [25]. Since high LET radiation, such as alpha radiation, causes more mode 1 damage, the resulting shape of the survival curve is a linear fit on a $\log$ scale. The $\beta$ term dominates when mode 2 (DSB resulting from 2 separate radiation events) is the most common mode of damage. At low doses, DNA repair mechanisms have time to repair some of the damage of a SSB before another break occurs in close enough proximity to cause a DSB. Thus, mode 2 becomes more likely to occur as the dose increases, since the probability of having two SSBs in close enough proximity is also increased. Another factor which influences the shape of the survival curve is the dose rate. For a low dose rate, SSBs have more time to repair. Generally, as the dose rate increases, the probability of DSBs caused by mode 2 increases. The fit of a sparsely ionizing type of radiation is dominated by the $\beta$ term at increasing doses or at increasing dose rates. A survival curve fit of a densely ionizing radiation is less affected by dose rate, since DSBs from 1 radiation track is the most probable mode of damage [27]. A typical survival curve for high and low LET radiation is illustrated in Figure 1-4. 


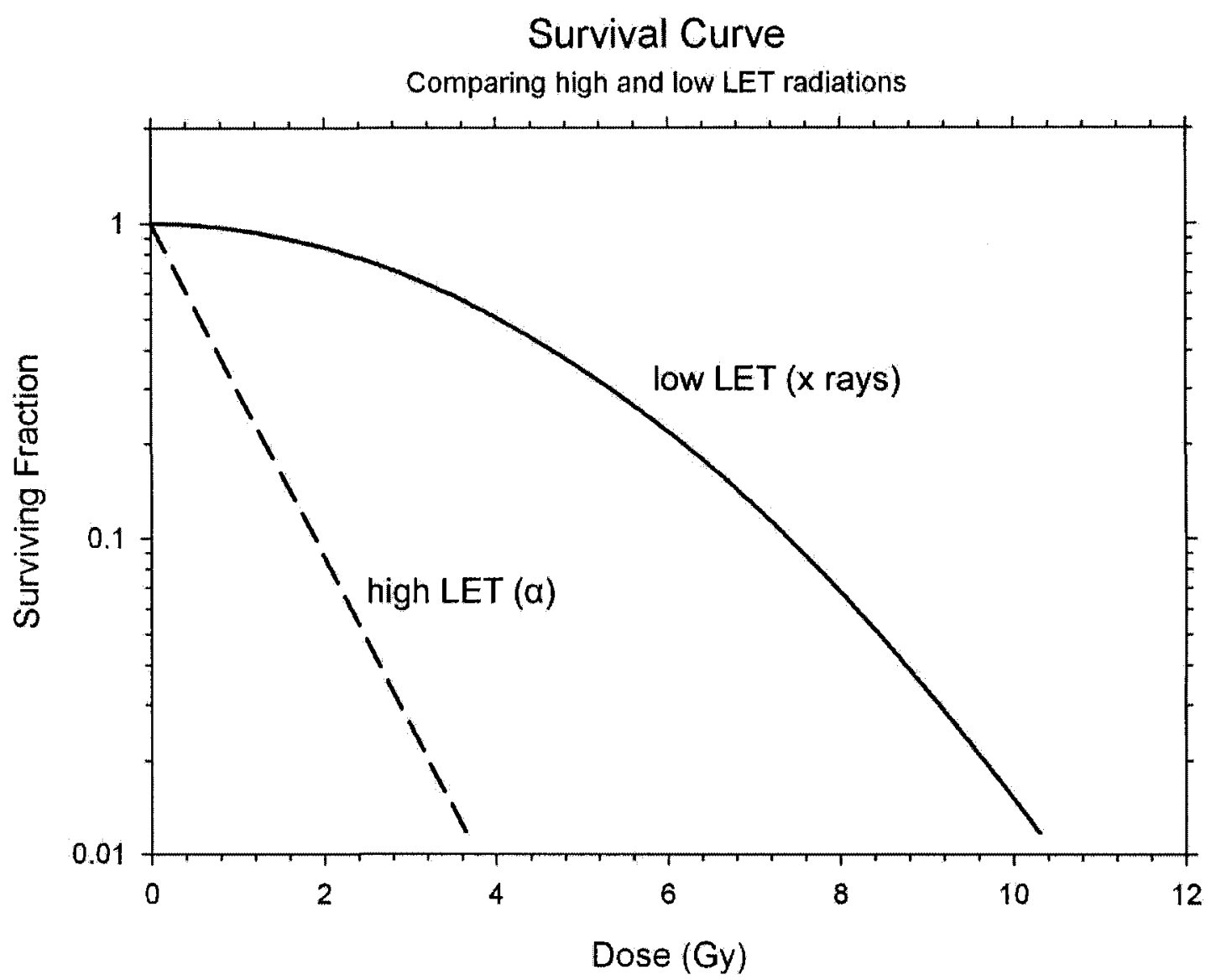

Figure 1-4: Typical survival curves for high and low LET radiation. The high LET radiation is densely ionizing, with DSBs caused by mode 1 damage, and the a component of the LQ model dominates, resulting in a linear shape. The low LET radiation is sparsely ionizing, with more DSBs resulting from mode 2 damage. The shape of the curve is dominated at high doses by the $\beta$ term, resulting in a quadratic shape. 


\subsubsection{Relative Biologic Effectiveness of Alpha and X Radiations}

Relative Biologic Effectiveness (RBE) is used to compare the biological effects of different types of damaging radiation. Traditionally, RBE is defined as the comparison of a test radiation dose $\left(D_{\text {test }}\right)$ to a reference radiation dose $\left(D_{\text {ref }}\right)$ required to achieve equal biological effect, Equation 8 .

$$
R B E=\frac{D_{r e f}}{D_{\text {test }}}
$$

Equation 8

A key issue in this definition is determining a point of equal biological effect. Commonly, survival curves are used for comparing two different types of radiation, and the doses for a surviving fraction chosen as the biological endpoint.

Different factors determine RBE: radiation quality (LET), dose, dose delivery method (number of dose fractions), dose rate, cell and tissue types and the chosen biological endpoint. RBE has a very interesting trend as LET changes. For increasing LET less than $10 \mathrm{keV} \cdot \mu \mathrm{m}^{-1}$, RBE increases slowly. Between 10 and 100 $\mathrm{keV} \cdot \mu \mathrm{m}^{-1}$, the RBE increases rapidly, reaching a maximum peak. After about 100 $\mathrm{keV} \cdot \mu \mathrm{m}^{-1}$, the RBE begins to decrease again. This maximum RBE value occurs for an LET value for which the spacing of ionizing interactions along a radiation track coincides with the approximate diameter of the DNA double helix. For higher LET values, the increase in dose does not result in an increased number of DSBs because the interaction events occur too close together. Figure 1-5 illustrates how RBE is affected by increasing LET. 


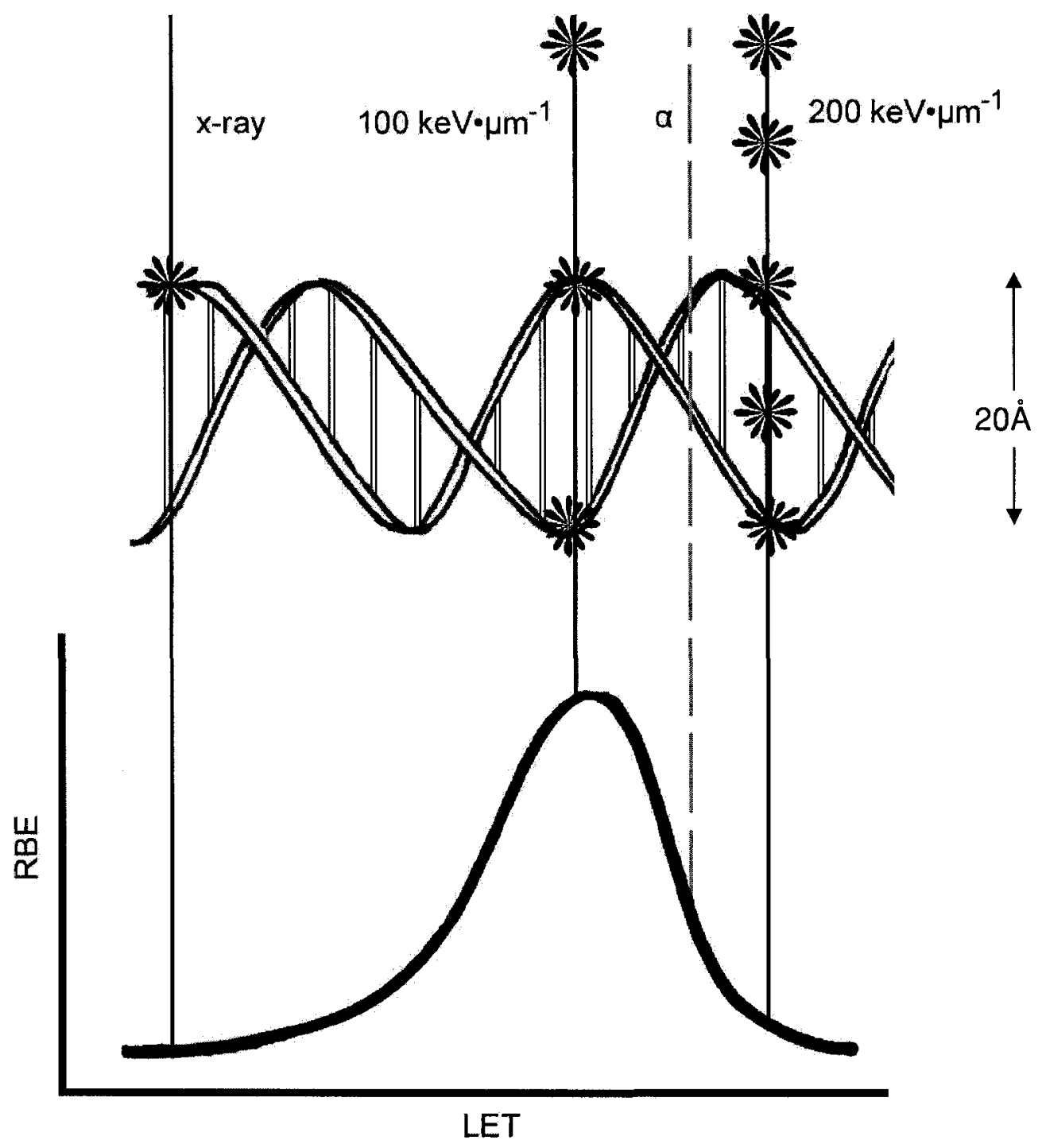

Figure 1-5: RBE as a function of LET: Illustration of why radiation with a LET value around $100 \mathrm{keV} \mu \mathrm{m}^{-1}$ results in the most damage, where the average separation between ionizing interactions coincides with the diameter of the DNA [20]. 


\subsection{Dosimetry}

\subsubsection{The Measurement of Energy Deposited by Radiation:}

When an ionizing beam of radiation interacts with matter, the quantity of interest to radiobiology is the absorbed dose (D). This is the energy absorbed per unit mass as a result of ionization and excitation of the matter along the track length [12]. Dose, D, is given by Equation 9 .

$$
D=\frac{d \bar{E}_{a b}}{d m}
$$

\section{Equation 9}

Where: $\quad \bar{E}_{a b}(\mathrm{~J})$ is the mean energy absorbed from ionizing radiation per unit mass $m(\mathrm{~kg})$. The SI unit for dose is called the gray (Gy) defined as $1 \mathrm{~J} \mathrm{~kg}^{-1}$.

For alpha particles, the most common form of detection is by liquid scintillation, which is performed by dissolving the source of alpha particles in a cocktail and measuring the scintillation radiation from the cocktail with photomultiplier tubes. In some situations, such as with a solid source, alpha scintillation is impractical due to geometric limitations. Furthermore, the dose to the cell nucleus is a difficult quantity to measure without disrupting the geometry of the experimental set-up. Therefore, alpha particle dosimetry calculations commonly use Monte Carlo simulations to model the value of dose [28-31].

\subsubsection{Monte Carlo Method}

The Monte Carlo (MC) method is a computational method based on a pseudo random number generator to simulate physical models. It is commonly used to model radiation events. MC simulations have been used to model and compare cellular irradiation techniques [30] and to design microbeam systems [31;32], as well as perform micro-dosimetric calculations [28;29]. 
One of the limiting factors for a $\mathrm{MC}$ simulation is the computational resources available. For large high energy physics (HEP) simulations, huge grids of networked computers are required for a reasonable calculation time [33]. With the increasing power of desktop computers, smaller scale simulations can be run within a laboratory without having to set up a vast network. Also, to improve efficiency, variance reduction techniques exist. Variance reduction techniques include but are not limited to Russian Roulette, geometry transformations, and production cuts [34].

Generally, the statistical uncertainty on a simulated value is taken to be the standard deviation of the mean. Therefore, to improve the precision of the method, the number of events needs to be increasing until they are statistically valid [35].

\subsubsection{SRIM2008}

In order to calculate the range of an ion in matter, a computational program can be used. Stopping Range of Ions in Matter (version 2008.1) (SRIM) is a MC toolkit which uses a binary collision algorithm to calculate the stopping range of ions of a defined energy or energy spectrum, in matter [36;37]. The incident particle (ion) and the target material can be defined by the user. Detailed material information can be included, such as densities, compound correction factors and damage information [36]. The collision calculations take into account screening from electron shells and long range interactions of the ion with target atoms.

There are two limitations of the SRIM toolkit; the first is that the particle is emitted from only one angle and one origin, and the second is that the target material can only be defined as infinite slabs of a variable thickness, but there is no other geometry information. 


\subsubsection{GEANT4}

There exist a number of $\mathrm{MC}$ toolkits with a vast range of functions. For the purpose of tracking alpha particles, the GEometry ANd Tracking (GEANT4) toolkit (version 4.9.1 p02) was used in this thesis. GEANT4 was developed for the purposes of High-Energy Physics (HEP) and is the simulation software used by many of the large laboratories, including but not limited to the Conseil Européen pour la Recherche Nucléaire (CERN) [38], the Stanford Linear Accelerator Center (SLAC) and the European Space Agency (ESA) [39]. The software was designed and developed by an international collaboration and has accumulated a large number of data libraries and functions [38]. While originally developed for HEP, GEANT4's libraries include data and functions that can be applied to low energy physics applications, including the capabilities of tracking alpha particles through matter [38].

One of the main benefits to using GEANT4 is that the entire simulation process can be defined by the user. The toolkit is a set of open-source files which can be edited and compiled to define the geometry and physics, as well as the output, as appropriate.

GEANT4 has previously been used to model alpha particle microbeams [29;31], and the description of the Centre d'Etudes Nucléaires de Bordeaux Gradignan (CENBG) microbeam simulations (MicroBeam) in France has been well described and included in the open-source GEANT4 installation code. The MicroBeam (MB) code defines a single alpha particle trajectory at a specified angle through a switching magnet, quadruplet, under an electric field and striking a single epidermal cell [31]. 


\subsubsection{GEANT4 Simulation Details}

A GEANT4 simulation can be thought of as an experiment, which starts when the beam is turned on. For any GEANT4 simulation to work, there are three $\mathrm{C}++$ classes which are mandatory; the Detector Constructor (DC), the Physics List (PL) and the Primary Generator (PG).

Prior to starting the simulation, the DC must define a model of the complete physical set-up, including all of the geometry and material details. The different objects in the set-up are described by volumes. Each volume is described by three classes: Solid Volume (SV), Logical Volume (LV) and Physical Volume (PV). The SV simply describes the shape and geometry of the volumes. The LV includes the geometrical information contained in the SV, but also defines the material properties of the volume. The volumes of interest, defined to be sensitive, are also described in the LV. Finally, the PV places a copy of the logical volume inside a larger containing volume, known as the mother volume. The only volume that does not have a mother is known as the World volume. Every other object is placed inside the World, with the centre of the object referenced by distance to the World origin [40].

The PL defines all of the physics processes of the particle interactions and the particle behaviour [38]. The physics processes need to be defined for when the particle is at rest, while it is in flight or after it has come to an interaction point. The PL also determines in which order the available processes are implemented. Every type of particle has to have a list of physics processes associated with it [38]. For the common types of physics processes, such as low energy electromagnetic physics, there are standard data libraries available which can be implemented to simplify the creation of the PL [40]. 
When the simulation is started, the PG defines the generation, including origin, initial trajectory, energy and momentum, of each primary particle, or event. The primary particle and all of the secondary particles it generates are tracked through each step of their respective trajectories. The next primary particle becomes the subsequent event. A track is maintained for every particle (primary and secondary), containing information about the particle including its identification, position, momentum, energy, mass, lifetime and other physical quantities. A collection of tracks for one particle is called a trajectory [38].

The particles progress through the simulation by taking steps, defined at the beginning and end of a step point. For every step a particle takes, physical quantities such as the energy lost on the step, as well as the time spent in flight are calculated. Therefore, particles with low LETs will have longer step sizes than those with high LETs. Whenever a step must cross a defined boundary in the simulation (such as a material interface), the step is ended on the boundary, and the subsequent step started on the other side [38].

GEANT4 does not use energy thresholds and a particle will be tracked until it loses all of its energy. Instead, GEANT4 uses production cuts, which are applied to the generation of a secondary particle, not to the termination of a particle already in existence. For example, if the production cut is $10 \mathrm{keV}$, no particle will be created with an initial energy lower than $10 \mathrm{keV}$. The production cuts can be defined for particular geometrical volumes or for different particles. These production cuts can be used as a variance reduction technique to avoid unnecessarily generating and tracking particles in great detail in regions of little interest to the user [38].

The simulation has the potential to generate a lot of data; it is left to the user to determine which information is important, such as the particle range or dose, 
and to generate output data files accordingly. The simplest output method is to generate text files filled with the data of interest, which can be analyzed later for graphs or histograms. Data can be extracted from the simulation at any time during the start or finish of a tracking action, an event or the entire simulation [40].

\subsection{Existing Alpha Radiation Exposure Methods}

In vitro irradiation using alpha particles has been used to study chromosome aberrations, the resultant genomic instabilities and bystander effects [41-46]. It has been shown that even at very low doses, alpha radiation can be very damaging, resulting in many times more DSB than from gamma- or x-radiation [43]. The transversal of a nucleus by a single alpha particle has a high probability of resulting in a mutation [44], since the induction and type of chromosome aberrations become more complex with increasing LET [45;46].

The calculation of RBE is still heavily debated; within a single reference there can be as many as four or five calculated RBEs for the same test and reference curves [47]. The choice of biological endpoint makes a difference; from Thomas et al [47] the measured RBE was 13.1 for $50 \%$ survival, 9.9 for $10 \%$ survival and 7.7 for $1 \%$ survival. If, rather than compare surviving fractions, the ratio of alpha coefficients in Equation 7 was used, the RBE was $14.0 \pm 1.0$. The implications of RBE for high LET radiation need to be studied further.

To assess the biological impact of high LET radiation, an alpha radiation exposure system (ARES) for in vitro study of cell cultures is required. While other exposure systems exist [48-52] there is a need for a simple, isotropic system that could be used to model in vitro the effects of alpha radiation. Some of the existing systems have complicated mechanical set-ups, with moving and rotating components, vacuum systems and helium gas filled chambers [48], which are 
more likely to have mechanical failures. The set-up and maintenance of this type of system can also be costly. Other systems include collimators [49-51], which provide a uniformity of fluence, but which reduce the number of transmitted alpha particles. A bench-top irradiator developed by Metting et al. [51] made use of stainless steel, Mylar-based culture dishes in which the Mylar was held tight with a sliding O-ring. Thomas et al. [47] used a form of ${ }^{210} \mathrm{Po}$ in solution to immerse the cells. The dosimetry of this method is complicated by uptake of ${ }^{210} \mathrm{Po}$ into the cells. An improved method which involved electroplating an alpha source $\left({ }^{210} \mathrm{Po}\right)$ to a disc, with Mylar based in-house cell culture dishes, was implemented by Thomas et al. with improved dosimetric result [47].

\subsection{Hypothesis}

The hypothesis of this thesis is that the design and fabrication of a simple alpha radiation exposure system for tissue culture with accurate dosimetry is feasible.

The system requirements were:

1.Source

- Should have a long half-life that provides a relatively stable activity and dose-rate over the course of an experiment.

- Should consist of high energy alpha particles with a long working life that does not need to be replaced often.

- The energy of the alpha particles should be similar to that of ${ }^{222} \mathrm{Rn}$.

- Should be sterilizable and durable in order to avoid contamination of the cell cultures and endure cell culture conditions.

- Should be calibrated and traceable to a national standards laboratory. 
2. Dishes

- Should allow the transmission of alpha particles with minimum degradation of the beam.

- Should be sterilizable to avoid cell culture contamination.

- Should support cell growth and culture over a sufficient period of time and varying cell culture conditions and processes.

- Should be time and cost efficient as many dishes are used in each experiment:

- Inexpensive

- Quick and easy to fabricate.

3. Dosimetry

- Should provide a dose-rate for the exposure system based on reliable and accurate modelling of the source, dishes and cells.

- Should be able to assess the feasibility of modifications to the system. 


\section{CHAPTER 2. MATERIALS AND METHODS}

\subsection{Sources}

\subsubsection{Gamma Source}

For exposures to gamma radiation, a Gammacell 40 (MDS Nordion, Ottawa, ON, Canada), consisting of two ${ }^{137} \mathrm{Cs}$ (half life $=30.23$ years) sources, one located above and one below the sample chamber, was used. The total activity of the sources, on July 18,1988 was $3.4 \mathrm{kCi}$. The central dose-rate to water was calibrated by MDS Nordion on May 26, 2008 by Fricke dosimetry and reported as 0.82 Gy $\mathrm{min}^{-1} \pm 5.2 \%[53]$.

All gamma exposures were performed within a period of 30 days. The relative change of activity of a radioactive source over a period of time is given by Equation 10:

$$
\frac{A}{A_{o}}=e^{-\ln 2 \cdot t / t_{1}} \frac{1}{2}
$$

\section{Equation 10}

Where: $\quad t=$ the given period of time

$$
t_{\frac{1}{2}}=\text { the half life of the radioactive source. }
$$

Using Equation 10, the change in activity over this period of time was determined to be $0.19 \%$ (Appendix A). As this falls within the uncertainty of the instrument, the dose-rate was assumed to be constant throughout the course of the experiments.

\subsubsection{Alpha Sources}

The alpha sources consisted of six discs of ${ }^{241} \mathrm{Am}\left(t_{\frac{1}{2}}=432.17 \pm 0.66\right.$ years) electroplated onto stainless steel with a contained activity of about $65 \mathrm{kBq}$ each 
(Eckert and Ziegler Isotope Products Ltd, Valencia, CA, USA). The mean energy of the alpha particle emitted from ${ }^{241} \mathrm{Am}$ is $5.48 \mathrm{MeV}$ (Table 2-1) [2]. Similarly to the ${ }^{137} \mathrm{Cs}$ sources, the long half life of the ${ }^{241} \mathrm{Am}$ source allowed the change in activity to be ignored over the course of the experiments.

\begin{tabular}{|r|r|}
\hline Energy (MeV) & \multicolumn{1}{|c|}{ Emission } \\
Probability (\%) \\
\hline 5.544 & 0.34 \\
\hline 5.512 & 0.20 \\
\hline 5.486 & 85.20 \\
\hline 5.469 & 0.04 \\
\hline 5.443 & 12.80 \\
\hline 5.417 & 0.01 \\
\hline 5.388 & 1.40 \\
\hline 5.322 & 0.01 \\
\hline Total Probability: & 100.00 \\
\hline Weighted mean: & $5.48 \mathrm{MeV}$ \\
\hline
\end{tabular}

Table 2-1: $\quad{ }^{241} \mathrm{Am}$ alpha energies and their emission probabilities, for emission probabilities $>0.01 \%$.

Each disc had an overall diameter of $50.8 \mathrm{~mm}$ and an active diameter of $45 \mathrm{~mm}$, with a thickness of $3.18 \mathrm{~mm}$. The ${ }^{241} \mathrm{Am}$ was electroplated to the surface of the disc, and the thickness of the electroplating was considered to be negligible. They were calibrated by the manufacturer and traceable to NIST. The discs are identified by individual disc numbers, and Table 2-2 describes each disc with its contained activity and surface emission (SE) rate at the time of calibration. As seen in Table 2-2, the activity of each source differed slightly from one to another. A conversion coefficient, Equation 11, was required to compensate for these slight differences in dose-rates. These conversions are also described in Table 2-2. In order to have comparable doses, Table 2-2 was used to find the appropriate exposure time for any given dose on any given source. 


$$
C=\frac{A_{\text {disc }}}{A_{E 6-513}}
$$

\section{Equation 11}

Where: $\quad \mathrm{C}=$ Conversion coefficient

$A_{\text {disc }}=$ Activity of the disc

$A_{E 6-513}=$ Activity of the reference disc, E6-513

The six discs were placed in a custom made nylon holder, with each disc inset slightly (Figure 2-1). The holder consisted of two $0.6 \mathrm{~cm}$ thick layers of nylon thermoplastic (nylon), held together by nylon screws. The top layer of nylon had 6 cut-out holes, diameter $5.2 \mathrm{~cm}$, spaced $1.9 \mathrm{~cm}$ apart. The bottom layer of nylon was a solid sheet. Together, the nylon formed a holder, with an inset cut-out for each disc source. Nylon was chosen as the holder material because it could be sterilized and irradiated repeatedly without degradation of the material properties [54]. Other plastics, such as polypropylene are more likely to become brittle and shatter after repeated sterilization and exposure to radiation [55].

Prior to each exposure, the discs and the nylon holder were sterilized by exposure to UV radiation (a minimum of 1 minute) and then misted with $70 \%$ ethanol (Commercial Alcohols, Brampton, ON, Canada) solution, which was left to evaporate in a biohazard hood.

The discs in their holder were then placed in a humidified incubation chamber $\left(37^{\circ} \mathrm{C}, 5 \% \mathrm{CO}_{2}\right)$ for the duration of the exposures. Whenever a disc was not in use, it was covered by a plastic lid. Edge effects and contributions from neighbouring sources were ignored since alpha particles have a high stopping power and do not bounce significantly from the surfaces of the plastic dishes, nor do they travel very far in air. Furthermore, the discs were inset $3.17 \mathrm{~mm}$ into the nylon holder and therefore the alpha particles did not have a direct trajectory to 
the cells of an adjacent dish. The only source contributions came from the disc upon which the dish was placed.

\begin{tabular}{|r|r|r|r|r|r|r|}
\hline Disc Number & E6-513 & E9-881 & E9-882 & E9-883 & E9-884 & E9-885 \\
\hline $\begin{array}{r}\text { Calibration } \\
\text { Date }\end{array}$ & 1-Nov-07 & 1-Apr-08 & 1-Apr-08 & 1-Apr-08 & 1-Apr-08 & 1-Apr-08 \\
\hline $\begin{array}{r}\text { Activity (kBq) } \\
\pm 3.0 \%\end{array}$ & 68.04 & 71.34 & 67.34 & 62.01 & 56.68 & 69.63 \\
\hline $\begin{array}{r}\text { Surface } \\
\text { Emission } \\
\text { Rate }\end{array}$ & $2.02 \times 10^{6}$ & $2.12 \times 10^{6}$ & $2.00 \times 10^{6}$ & $1.84 \times 10^{6}$ & $1.69 \times 10^{6}$ & $2.07 \times 10^{6}$ \\
$\begin{array}{r}\left(\alpha \text { min }^{-1}\right. \\
\text { in } 2 \pi) \\
\pm 3.0 \%\end{array}$ & & & & & & \\
\hline $\begin{array}{r}\text { Conversion } \\
\text { coefficient }\end{array}$ & 1.00 & 1.05 & 0.99 & 0.91 & 0.83 & 1.02 \\
\hline $\begin{array}{r}\text { Time (min): } \\
5\end{array}$ & 5.00 & 4.77 & 5.05 & 5.49 & 6.00 & 4.89 \\
\hline 30 & 30.00 & 28.61 & 30.31 & 32.92 & 36.01 & 29.31 \\
\hline 60 & 60.00 & 57.22 & 60.62 & 65.83 & 72.03 & 58.63 \\
\hline 90 & 90.00 & 85.84 & 90.94 & 98.75 & 108.04 & 87.94 \\
\hline 120 & 120.00 & 114.45 & 121.25 & 131.67 & 144.05 & 117.26 \\
\hline 240 & 240.00 & 228.90 & 242.49 & 263.34 & 288.10 & 234.52 \\
\hline & & & & & & \\
\hline
\end{tabular}

Table 2-2: Alpha source characteristics, including contained activity and SE rate (at time of calibration date), as well as the associated conversion coefficients. 


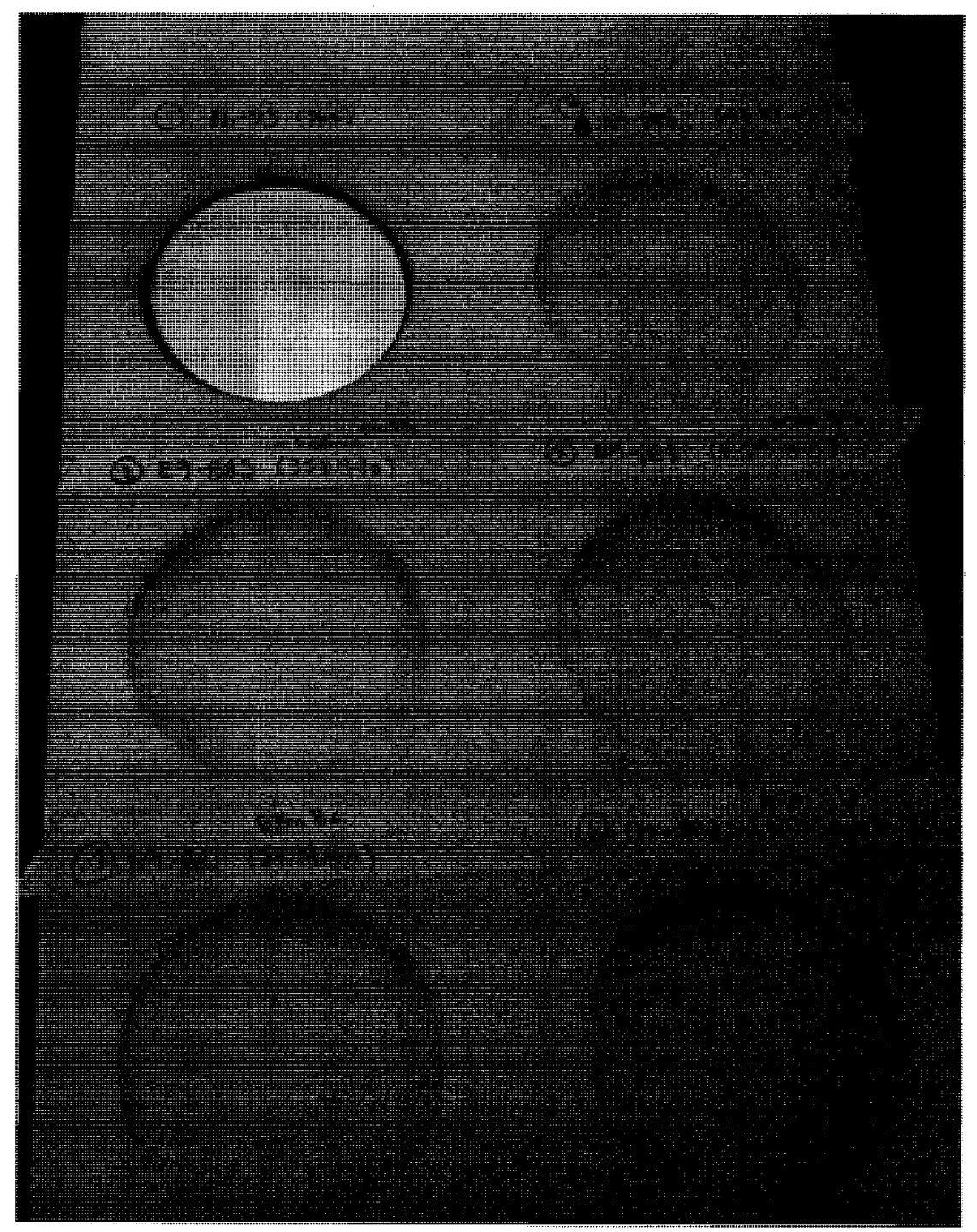

Figure 2-1: Source holder with the following dimensions: $15.2 \mathrm{~cm} \times 30.5 \mathrm{~cm} \times$ $1.3 \mathrm{~cm}$ overall; 6 cut-out holes of diameter $5.2 \mathrm{~cm}$ spaced $1.9 \mathrm{~cm}$ apart. The cut-outs are $0.6 \mathrm{~cm}$ deep. The holder is made entirely of nylon. 


\subsection{Dishes}

The cells were maintained in tissue culture flasks with a surface area of $75 \mathrm{~cm}^{2}$ (T75), canted neck with ventilated caps (VWR, Mississauga, ON, Canada). A small fraction of the maintained cells were then harvested and relocated into similar, smaller flasks, with a surface area of $25 \mathrm{~cm}^{2}$ (T25; VWR) for irradiation. Further cell culture methodology is discussed in Section 2.4. These flasks are made of polystyrene and their bases have a thickness of $1.0 \mathrm{~mm}$. While gamma radiation easily passes through this material, alpha radiation does not, making these dishes unsuitable for alpha exposures.

To address this issue, the cells were cultured in thin Mylar based plastic dishes (MD) for the alpha exposures. The MD consisted of a three piece plastic sleeve; inner and outer sleeves, with a pierced cap that fit tightly to the dish (Chemplex Industries, Palm City, FL, USA). The inner diameter of the dish was $35.8 \mathrm{~mm}$ and the outer diameter was $39.9 \mathrm{~mm}$, with a height of $29.6 \mathrm{~mm}$. Two Mylar membranes (Chemplex Industries), each $76.2 \mathrm{~mm}$ in diameter and $2.5 \mu \mathrm{m}$ thick, were gently placed across the bottom opening of the inner sleeve. The outer sleeve was then slid over the membranes, leaving the membranes sandwiched between the two sleeves and stretched tightly across the bottom opening (Figures 2-2 and 2-3). The MD pieces were autoclaved in loosely sealed glass jars at $121^{\circ} \mathrm{C}$ for 25 minutes, and then left to cool to room temperature before putting the dish together in a biohazard hood in order to maintain sterility [22]. To protect the integrity of the Mylar base, the dishes were placed in $60 \mathrm{~mm}$ culture dishes (Corning, New York, New York, USA), with a polystyrene base $1 \mathrm{~mm}$ thick, when they were not being exposed to alpha radiation.

The cells were irradiated in two different kinds of containers, T25 and MD. The set up of the gamma irradiator is such that photons from the two ${ }^{137} \mathrm{Cs}$ sources must traverse different dish geometries to reach the monolayer of cells. Equation 
12 defines the attenuation of a photon beam of energy, $\mathrm{E}$, through a material of thickness $x$. Using Equation 12, the attenuation through each material was calculated (see Appendix A) and shown in Table 2-3.

$$
I=I_{0}(E) e^{-\mu(E) x}
$$

Equation 12

Where: $\quad I=$ intensity of the photon beam at depth $x$

$I_{0}(E)=$ initial intensity of the beam of energy $E$, and

$\mu(E)=$ attenuation coefficient of the material as a function of $E$.

Using the NIST database for the continuous slowing down approximation (CSDA) range through a material [56], the range of the alpha particles in Mylar was determined to be $50 \mu \mathrm{m}$ (Table 2-4). As the Mylar membrane was only 5.0 $\mu \mathrm{m}$ thick and alpha particles do not scatter easily, all of the alphas were able to penetrate the membrane and into the layer of adherent cells. 

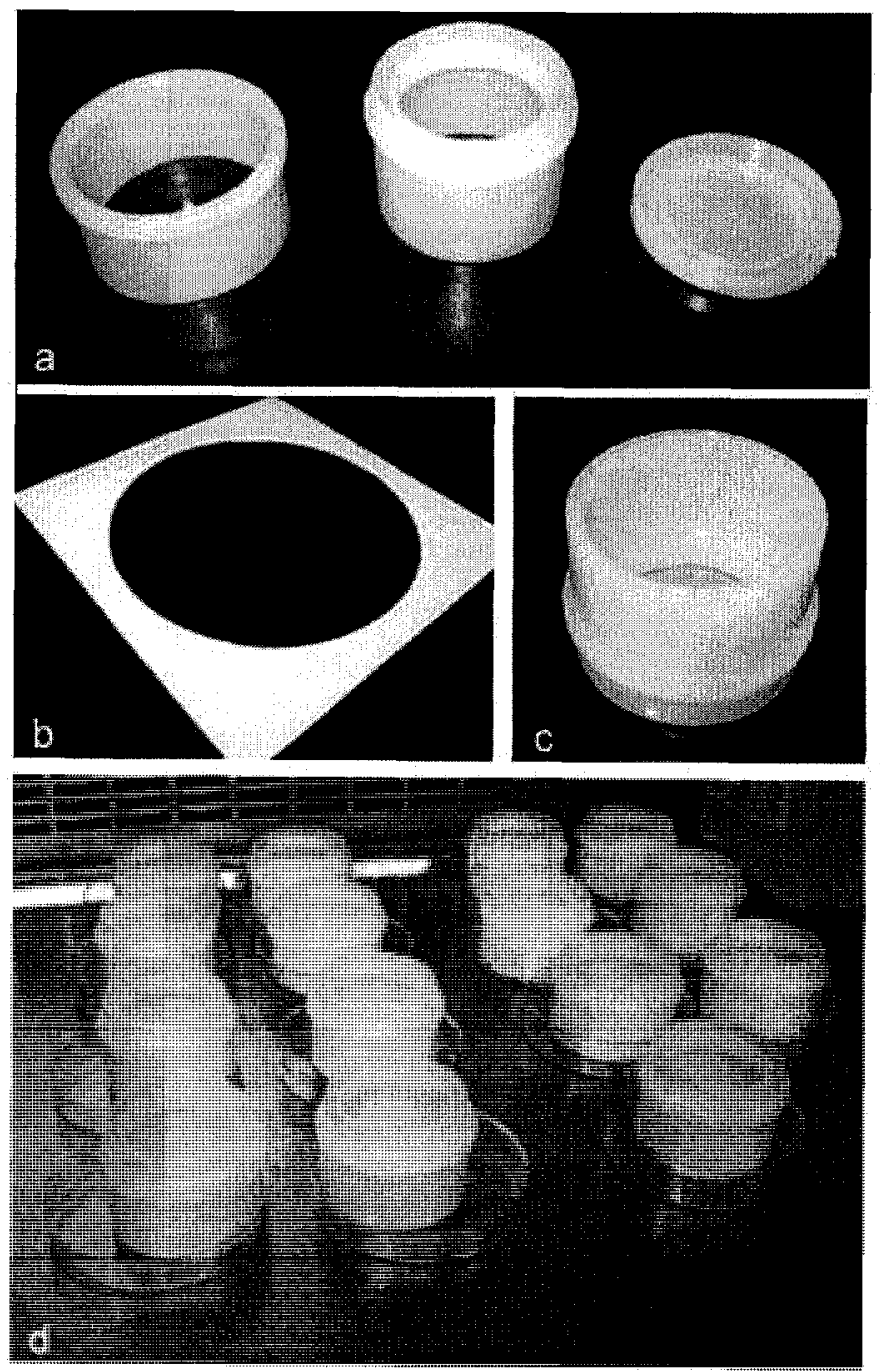

Figure 2-2: Mylar dishes: a) 3 plastic pieces, from left to right, the outer sleeve, inner sleeve and ventilated cap; b) a single sheet of $2.5 \mu \mathrm{m}$ Mylar in a white cardboard holder; c) the MD put together and upside down to show the Mylar stretched tight across the base opening; d) MDs, without caps on, placed in individual plastic 60 $\mathrm{mm}$ dishes to protect the Mylar membrane during transportation and incubation of the dishes. 


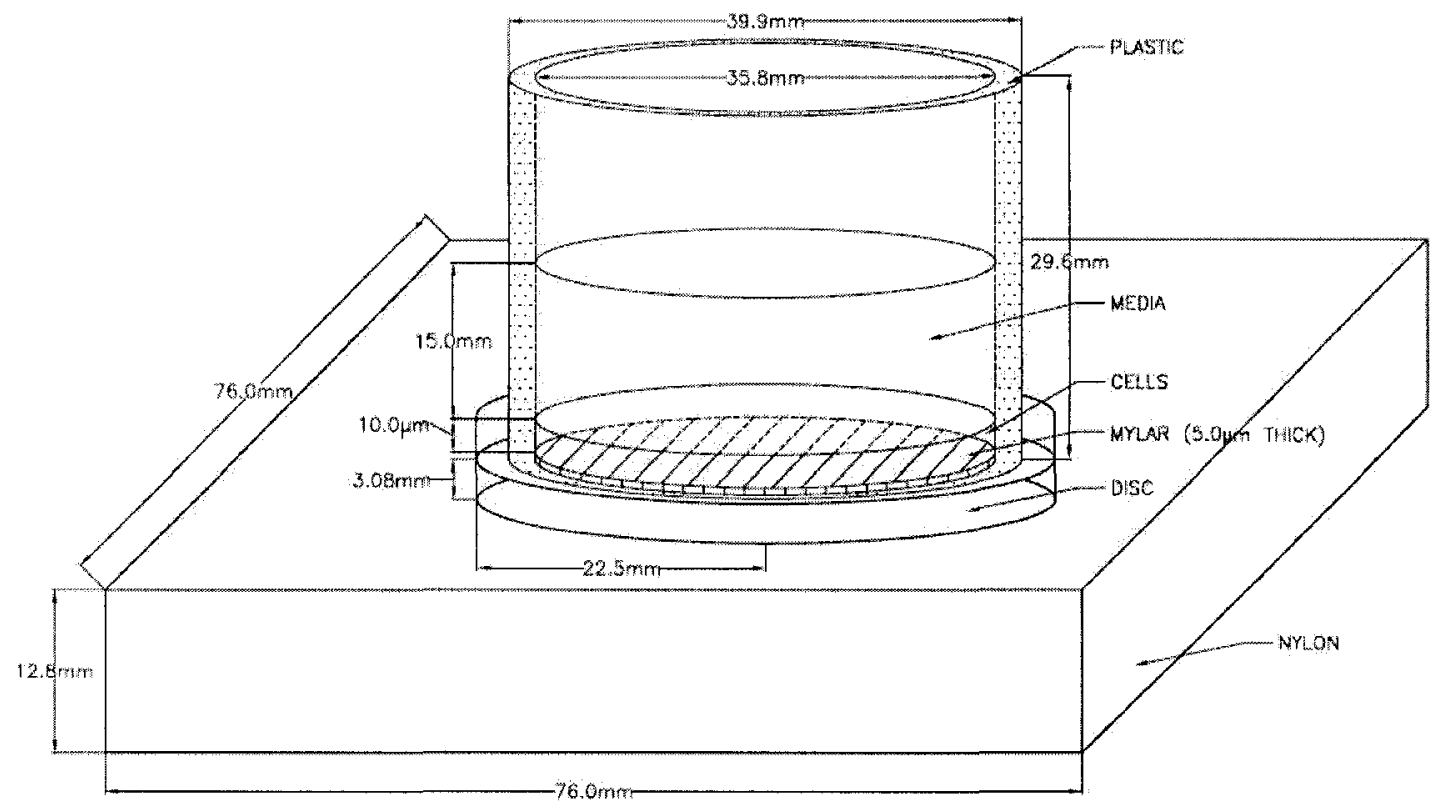

Figure 2-3: Schematic of an MD, containing a monolayer of cells and media, sitting upon a source disc, inset into a nylon holder. The schematic is not to scale as the Mylar and cells are too small to be seen relative to the rest of the material. The polystyrene, ventilated cap, was not modeled, and is not included in the schematic. 


\begin{tabular}{|c|c|c|c|c|}
\hline \multirow{2}{*}{\multicolumn{5}{|c|}{$\frac{\text { Gamma Irradiation of T25 }}{\mathrm{E}=662 \mathrm{keV}}$}} \\
\hline & & & & \\
\hline & Material & $\begin{array}{l}\text { Thickness } \\
(\mathrm{cm})\end{array}$ & $\begin{array}{c}\mu(\mathrm{E}) \\
\left(\mathrm{cm}^{-1}\right)\end{array}$ & Attenuation \\
\hline From below & Polystyrene & 0.1 & $8.67 \times 10^{-2}$ & 0.01 \\
\hline From above & Polystyrene & 0.1 & $8.67 \times 10^{-2}$ & 0.01 \\
\hline & Air & 2.0 & $9.29 \times 10^{-5}$ & 0.00 \\
\hline & Media & 0.5 & $8.57 \times 10^{-2}$ & 0.04 \\
\hline \multicolumn{4}{|c|}{ Total Average Attenuation: } & $3 \%$ \\
\hline 28 & Gamma & & $\mathrm{MD}$ & 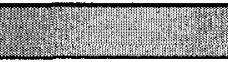 \\
\hline \multicolumn{5}{|c|}{$\mathrm{E}=662 \mathrm{keV}$} \\
\hline & Material & $\begin{array}{l}\text { Thickness } \\
(\mathrm{cm})\end{array}$ & $\begin{array}{c}\mu(\mathrm{E}) \\
\left(\mathrm{cm}^{-1}\right)\end{array}$ & Attenuation \\
\hline \multirow[t]{2}{*}{ From below } & Polystyrene & 0.1 & $8.67 \times 10^{-2}$ & 0.01 \\
\hline & Mylar & 0.0005 & $1.18 \times 10^{-1}$ & 0.00 \\
\hline \multirow[t]{3}{*}{ From above } & Polystyrene & 0.2 & $8.67 \times 10^{-2}$ & 0.02 \\
\hline & Air & 1.0 & $9.29 \times 10^{-5}$ & 0.00 \\
\hline & Media & 1.5 & $8.57 \times 10^{-2}$ & 0.13 \\
\hline \multicolumn{4}{|c|}{ Total Average Attenuation: } & $8 \%$ \\
\hline
\end{tabular}

Table 2-3: Dish materials and thicknesses for both the T25 and MD. The total attenuation of the gamma source from below and above, respectively are calculated. 


\begin{tabular}{|l|r|r|r|}
\hline Material & $\begin{array}{c}\text { Density } \\
\left(\mathrm{g} \mathrm{cm}^{-3}\right)\end{array}$ & $\begin{array}{c}\text { CSDA Range } \\
\left(\mathrm{g} \mathrm{cm}^{-2}\right)\end{array}$ & $\begin{array}{c}\text { Range of 5.48 MeV } \\
\text { alpha particle }\end{array}$ \\
\hline Air & $1.205 \times 10^{-3}$ & $5.020 \times 10^{-3}$ & $4.166 \mathrm{~cm}$ \\
\hline Mylar & 1.400 & $4.646 \times 10^{-3}$ & $33.19 \mu \mathrm{m}$ \\
\hline Nylon & 1.140 & $4.101 \times 10^{-3}$ & $35.97 \mu \mathrm{m}$ \\
\hline Polystyrene & 1.060 & $4.262 \times 10^{-3}$ & $40.21 \mu \mathrm{m}$ \\
\hline
\end{tabular}

Table 2-4: Stopping range of $5.48 \mathrm{MeV}$ alpha particles through various materials. Calculations (Appendix A) are based on plots generated by NIST's database ASTAR [56].

\subsubsection{Collagen}

In order to promote the adherence of certain cell lines to the Mylar membranes, a collagen solution was used to coat the Mylar. The collagen was of type 1, Rat Tail Collagen (BD Biosciences, Bedford, MA, USA). The solution was made by diluting the collagen to $50 \mu \mathrm{g} \cdot \mathrm{mL}^{-1}$ with $0.02 \mathrm{~N}$ acetic acid (Fisher Scientific, Fair Lawn, NJ, USA). The solution was then filtered using a presterilized disposable vacuum filter (Steriflip, Millipore Corporation, Bedford, MA, USA) with a membrane pore size of $0.45 \mu \mathrm{m}$, and then applied to each dish with a pipette, for a concentration of $5 \mu \mathrm{g} \mathrm{cm}^{-2}$. The dishes were left to dry at room temperature for a day, then rinsed well with phosphate buffered saline (PBS) (Gibco, Carlsbad, CA, USA) to neutralize any remaining acetic acid without disturbing the collagen. After rinsing, the dishes were used immediately.

\subsection{Cell Culture}

The growth of a monolayer of confluent cells was important in order to simplify the modeling of the cell culture for the dosimetry calculations. For this reason, adherent cell lines, which attach to the bottom surface of the dish and tend to spread out, were chosen over suspension cells, which rest on the surface but are 
free to shift and are easily disturbed. Two cell lines were considered, a brain glioblastoma (U-87 MG), and a lung carcinoma (A-549) (ATCC, Manassas, VA, USA).

The cell cultures were grown in the appropriate dishes (T75, T25 or MD) and remained submerged in nutrient baths (complete media); A-549s used F-12K Medium (Kaighn's Modification of Ham's F12) with 2mM L-Glutamine (ATCC), and U87-MGs used MEM Alpha with 2mM L-Glutamine (Minimum Essential Medium, Alpha Medium 1x) (Gibco). 10\% volume per volume (v/v) Fetal Bovine Serum (FBS) (Sigma-Aldrich, Oakville, ON, Canada) was added to both sets of media.

Cells were maintained in a $\mathrm{CO}_{2}$ water jacketed incubator (Nuaire US Autoflow, Plymouth, MN, USA) with a controlled atmosphere, temperature, and a high humidity level. The incubator settings were $37^{\circ} \mathrm{C}$ and $5 \% \mathrm{CO}_{2}$. All cell culture work was otherwise performed in a sterilized laminar flow biohazard hood (hood) (Microzone Corporation, Nepean, ON, Canada). The hood was sterilized before and after any cell culture work by turning on a UV light for a minute, as well as misting the entire surface with $70 \%$ ethanol.

\subsubsection{Trypsin and Cell Count}

Trypsin is an enzyme commonly used to dissociate a monolayer of cells. The media was aspirated from the dish using Pasteur pipettes and a vacuum flask, and the cells were washed with $1 \mathrm{~mL}$ of PBS per dish. The PBS was aspirated, and $0.75 \mathrm{~mL}$ of $0.25 \%$ trypsin-ethylenediaminetetraacetic acid (EDTA) (1x) (Gibco) added to each flask. The flasks were returned to the incubator.

After 5 minutes, the cells were examined under a microscope (x100 magnification) to verify that they had detached from the surface and from each 
other. In the hood, the trypsin-EDTA was neutralized with $5.0 \mathrm{~mL}$ of complete media. A single cell suspension was created by repeated pipetting over the monolayer cell surface. If further dilution was required, $250 \mu \mathrm{L}$ of the cell suspension was then diluted into previously prepared $50 \mathrm{~mL}$ centrifuge tubes (VWR) containing $40 \mathrm{~mL}$ of complete media.

To determine the cell concentration, $100 \mu \mathrm{L}$ was removed from the cell suspension and added to accuvettes filled with $10 \mathrm{~mL}$ of isoton II diluent (Beckman Coulter. Toronto, ON, Canada). The accuvettes were capped and gently inverted 3 times, and then placed in the Z2 Coulter Particle Counter \& Size Analyzer (Coulter counter; Beckman Coulter) that counts cell concentration (in cells $\mathrm{mL}^{-1}$ ). The Coulter counter probe was rinsed with double distilled water $\left(\mathrm{ddH}_{2} \mathrm{O}\right)$ after every sample was run. Blank samples were run in between each count to ensure that background counts were small (less than 5\%) and to flush the system of any residual cells. The Coulter counter size settings were adjusted depending upon the cell line being counted. The settings are listed in Table 2-5.

\begin{tabular}{|l|r|r|}
\hline Cell Type & Minimum diameter $(\mu \mathrm{m})$ & Maximum diameter $(\mu \mathrm{m})$ \\
\hline U87-MG & 7.500 & 20.000 \\
\hline A-549 & 9.068 & 20.000 \\
\hline
\end{tabular}

Table 2-5: Coulter counter settings for cell types U87-MG and A-549.

\subsubsection{Growth Curves}

In order to characterize the growth of the cells on MDs as compared to a typical cell culture dish of polystyrene plastic, growth curve experiments were performed. The first experiment was to establish the growth curves for a recommended seeding ( $1 \times$ SD) and an increased seeding density ( $3 x$ SD). The 
second experiment established the growth curves for the MDs with collagen (C) and without a collagen coating (NC). The polystyrene containers were 6-well plates (6WP) (Corning), with the same growing surface as the T25 dishes. Since the different dishes had different surface areas (SA), the seeding densities were established in units of cells per surface area. Table 2-6 contains the surface areas and initial seeding densities for each growth curve.

\begin{tabular}{|l|r|r|r|}
\hline \multicolumn{3}{|c|}{ Growth Curves: Comparing Seeding Densities } \\
\hline \multirow{2}{*}{ Dish } & $\begin{array}{c}\text { Surface } \\
\text { area } \\
\end{array}$ & \multicolumn{2}{|c|}{ Initial seeding density } \\
\cline { 3 - 4 } & $\left(\mathrm{mm}^{2}\right)$ & $\left(\right.$ cells $\left.\mathrm{mm}^{-2}\right)$ & (cells dish $\left.{ }^{-1}\right)$ \\
\hline 6WP & 903 & 100 & $9.03 \times 10^{4}$ \\
\hline MD (1 SD) & 1250 & 100 & $1.25 \times 10^{5}$ \\
\hline MD (3 SD) & 1250 & 300 & $3.75 \times 10^{5}$ \\
\hline Growth Curves: With (C) and Without Collagen (NC) \\
\hline 6WP & 903 & 100 & $9.03 \times 10^{4}$ \\
\hline MD (C) & 1250 & 100 & $1.25 \times 10^{5}$ \\
\hline MD (NC) & 1250 & 100 & $1.25 \times 10^{5}$ \\
\hline
\end{tabular}

Table 2-6: Seeding densities used for each of six growth curves.

The dishes to be used for the six growth curves were prepared in advance. For each growth curve, 5 counting samples were required, where each dish (or well in the case of $6 \mathrm{WPs}$ ) was used once as a counting sample and discarded. Using a T75 in log phase, the cells were trypsinised, diluted and the cell concentration of the suspension determined. The dishes were seeded with the appropriate volume of suspension, as determined by Equation 13 . 


$$
V_{\text {seed }}(\mu \mathrm{L})=\frac{\text { Number of cells to seed } \cdot 10^{3}\left(\frac{\mu \mathrm{L}}{\mathrm{mL}}\right)}{\text { Cell concentration }\left(\frac{\text { cells }}{\mathrm{mL}}\right)} \quad \text { Equation } 13
$$

All the dishes were placed in the incubator at $37^{\circ} \mathrm{C}, 5 \% \mathrm{CO}_{2}$. After 9, 24, 45, 78, and 102 hours, a sample dish (or well) from each growth curve was removed from the incubator, trypsinised and the concentration determined using the Coulter Counter. Each sample was counted in triplicate, and the average of the three counts was used as the cell concentration, with an uncertainty equal to the standard deviation of the mean. The optimum time for irradiation was determined from a plot of the number of cells per surface area versus time after initial seeding.

Unlike a targeted microbeam exposure system [57], the electroplated discs had an isotropic beam and the trajectory of the alpha particles was unknown. In order to maximize the number of nuclei hit by alpha particles, the cells were irradiated when they were $90 \%$ confluent in order to ensure that most of the surface area of the dish was covered.

\subsection{Clonogenic Assay}

\subsubsection{Irradiation}

For gamma exposures, the following dose points were used; 0.0, 0.5, 1.0, 1.5, 2.0, $4.0,6.0$, and $8.0 \mathrm{~Gy}$, for a total of 8 dose points. For the alpha exposures, the time of exposure was kept constant, so that it would be easily comparable for all alpha exposures, and easily converted to a dose. The times of exposures were nominally; $0,5,30,60,90,120$ and $240 \mathrm{~min}$, for a total of 7 dose points.

The gamma exposures were performed on $\mathrm{T} 25$ and $\mathrm{MD}$, and the alpha exposures on MD only. One dish (T25 or MD) was prepared for each dose. The T25 were seeded at a cell concentration of $7.5 \times 10^{5}$ cells per T25, and the MD were seeded 
at a cell concentration of $3.8 \times 10^{5}$ cells per MD, both having the same concentration of 300 cells $\mathrm{mm}^{-2}$.

Cells were irradiated 48 hours after seeding. At that time, the cells had reached approximately $90 \%$ confluence, and contained approximately $10^{6}$ cells, or roughly 800 cells $\mathrm{mm}^{-2}$. Table $2-7$ contains the time of exposures for the alpha exposures.

\subsubsection{Plating}

The irradiated dishes were trypsinised and diluted into a single cell suspension, of which the cell concentration was determined. For the clonogenic assay, a small fraction of cells were transferred to $60 \mathrm{~mm}$ culture dishes (plates). Three plates were labelled and filled with $3 \mathrm{~mL}$ complete media for each dose point. The number of cells required for each dose point was calculated based on an estimated surviving fraction using Equation 14 and is shown in Table 2-7. From this number, the volume required was calculated using Equation 15 and the volume was added to the $3 \mathrm{~mL}$ of complete media already in each plate. The suspension was pipetted repeatedly to uniformly mix the cells, and the plate was gently moved in a figure eight pattern to distribute the cells evenly over the plate. The plates were placed in the sterilized incubator at $37^{\circ} \mathrm{C}$ and $5 \% \mathrm{CO}_{2}$ for two weeks.

$$
\text { Number of cells to plate }=\frac{\text { Expected colonies }}{S F_{\text {estimate }} \cdot \frac{P E}{100}}
$$

\section{Equation 14}

Where: $\quad S F_{\text {estimate }}=$ estimated surviving fraction

$$
P E=\text { plating efficiency }
$$




$$
\text { Volume }(m L)=\frac{\text { Number of cells to plate }}{\text { cell concentration }\left(\frac{\text { cells }}{m L}\right)} \quad \text { Equation } 15
$$

\begin{tabular}{|r|r|}
\hline \multicolumn{2}{|c|}{ Radiation Type: Alpha } \\
\hline $\begin{array}{c}\text { Time of } \\
\text { Exposure } \\
\text { (min) }\end{array}$ & Number of cells to plate \\
\hline 0 & 150 \\
\hline 5 & 250 \\
\hline 30 & 350 \\
\hline 60 & 1000 \\
\hline 90 & 6000 \\
\hline 120 & 12000 \\
\hline 240 & 20000 \\
\hline
\end{tabular}

\begin{tabular}{|r|r|}
\hline \multicolumn{2}{|c|}{ Radiation Type: Gamma } \\
\hline $\begin{array}{c}\text { Dose } \\
\text { (Gy) }\end{array}$ & Number of cells to plate \\
\hline 0 & 125 \\
\hline 0.5 & 148 \\
\hline 1.0 & 162 \\
\hline 1.5 & 195 \\
\hline 2.0 & 224 \\
\hline 4.0 & 456 \\
\hline 6.0 & 1150 \\
\hline 8.0 & 3785 \\
\hline
\end{tabular}

Table 2-7: Plating numbers for alpha and gamma irradiation of A-549 cells.

\subsubsection{Staining, Washing and Counting}

After two weeks, the dishes were removed from the incubator. The media was discarded and the cells were stained with methylene blue (70\% ethanol and $0.4 \%$ $\mathrm{w} / \mathrm{v}$ methylene blue trihydrate (Sigma-Aldrich)) for 30 minutes. The stain was poured off and the dishes carefully rinsed in cool water to remove the excess stain but not the colonies and left to air dry prior to counting.

The colonies were counted manually on an illuminated standard colony counter (Bantex Corporation, Burlingame, CA, USA). Colonies containing more than 50 cells were counted for each dish. 
Using Equation 16, the surviving fraction was calculated for each of the three dishes per dose point, and then averaged for each dose point. The uncertainty on the average was calculated as the standard deviation on the average. The results were then plotted and fit by an iterative least squares regression algorithm to an adapted LQ model of cell survival (Equation 17).

$$
\begin{aligned}
& S F_{n o P E}=\frac{\text { Number of colonies counted }}{\text { Number of cells seeded }} \\
& S F=e^{-\alpha D-\beta D^{2}-c}
\end{aligned}
$$

Equation 16

Equation 17

Where: $\quad c=y$-intercept

The $y$-intercept, $c$, was found from the fit of the curve, and this value was then used as the PE of the data, since for a dose of $0 \mathrm{~Gy}$, there should be $100 \%$ survival. Setting the y-intercept of the linear-quadratic curve to zero, determines the PE without unnecessary weighting on the 0 Gy dose point. The surviving fraction was recalculated with Equation 5, now including the calculated PE, plotted and refit according to Equation 7.

Each survival curve (T25 exposed to gamma irradiation, MD exposed to gamma irradiation, MD exposed to alpha irradiation) was repeated independently at least five times. The results of each survival curve were averaged and again fit by the iterative least squares regression algorithm to Equation 17. The 95\% confidence intervals were plotted, and $\alpha$ and $\beta$ values determined from the fit. 


\subsection{Dosimetry}

\subsubsection{SRIM2008}

A SRIM2008 simulation was used to verify the transmittance of the alpha particles through the Mylar, and to calculate the expected location of the Bragg peak. The incident ion was defined to be a helium nucleus, and the target material was set to be three layers: $5 \mu \mathrm{m}$ Mylar, $10 \mu \mathrm{m}$ cell monolayer (epidermal tissue) and over $200 \mu \mathrm{m}$ of water equivalent media. 10000 events were run, with a starting energy of $5.48 \mathrm{MeV}$ and at an incident angle of $0^{\circ}$.

The output of the simulation included a plot of the depth (z-axis) versus lateral scatter (y-axis), and a list of the stopping range (and position) of all the particles. The mean stopping range was calculated, with an uncertainty equal to the standard deviation of the mean.

\subsubsection{GEANT4}

The GEANT4 MB [31] code was adapted to model the ARES set-up. The entire program was started in the run manager, which controlled the flow of the simulation and called all the corresponding functions. From the run manager, the Detector Constructor (DC), the Physics List (PL) and the Primary Generator (PG) were initiated. Also initiated were action classes; each contained specific instructions to be carried out during a simulation, an event, while tracking, and while stepping. Figure 2-4 provides a diagram which illustrates the associated classes and functions.

The GEANT4 toolkit has a few pseudo random number generators available. The ARES simulations used the RanecuEngine algorithm for generating random numbers. This engine was originally written for a HEP algorithm library, and the initialization used a multiplicative congruential generator. The formula constants 
(L'Ecuyer's) and algorithms are described in F. James' review of random number generators [58]. The period of this algorithm is on the order of $2 \times 10^{18}$, which was more than sufficient for a simulation on the scale of $5 \times 10^{5}$ primary events.

\subsubsection{Detector Constructor (DC)}

Since the MB geometry differed vastly from the ARES geometry, the DC was rewritten almost entirely for ARES. The nucleus and cytoplasm material definitions were kept. Otherwise, the ARES DC defined the materials and objects required for the ARES model. All volumes with the exception of the cell volume were created using basic geometric shapes. The cell volume was created in two parts; a cylindrical tube of cytoplasm material, with a density of $1.00 \mathrm{~g} \mathrm{~cm}^{-3}$, and with a radius of $5 \mu \mathrm{m}$ and a height of $10 \mu \mathrm{m}$ was created first, and a smaller cylindrical tube of nucleus material, with a density of $1.13 \mathrm{~g} \mathrm{~cm}^{-3}, 4 \mu \mathrm{m}$ in diameter and $10 \mu \mathrm{m}$ tall, was placed inside. The nucleus made up $16 \%$ of the cell volume. The cell was then replicated roughly 13 million times, in order to fill the area of the MD. Table 2-8 details the material and geometry values used in the model. The physical placement details the location of the centre of the volume with respect to the origin of the World volume.

No external fields were required, so the logical volume simply detailed materials and sensitive volumes (detector). Since it is commonly accepted that DNA is the primary target for radiation damage, the nuclei of the cells were defined to be the detectors. 


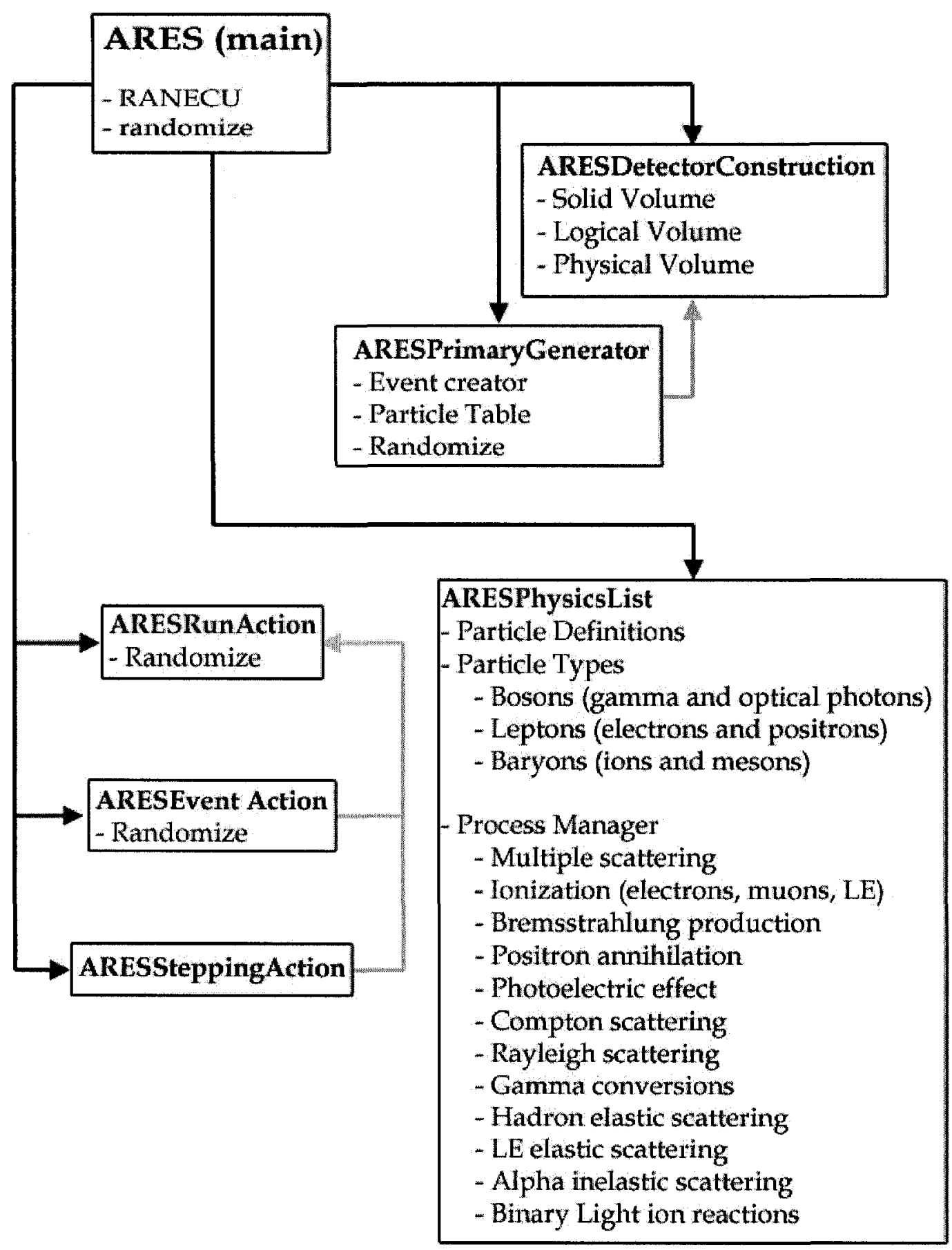

Figure 2-4: Adapted class diagram illustrating the dependent classes used in the ARES code. GEANT4 backend classes are not illustrated. 


\begin{tabular}{|c|c|c|c|c|c|c|}
\hline \multirow[b]{2}{*}{ Volume } & \multirow[b]{2}{*}{ Dimensions } & \multirow[b]{2}{*}{ Material } & \multirow{2}{*}{$\begin{array}{l}\text { Mother } \\
\text { Volume }\end{array}$} & \multicolumn{3}{|c|}{ Physical Placement } \\
\hline & & & & $x(\mathrm{~mm})$ & $y(\mathrm{~mm})$ & $\mathrm{z}(\mathrm{mm})$ \\
\hline World & $2 \mathrm{~m} \times 2 \mathrm{~m}$ & Air & none & 0.0000 & 0.0000 & 0.0000 \\
\hline Holder & $\begin{array}{c}76 \mathrm{~mm} \times 76 \\
\mathrm{~mm} \times 12.8 \mathrm{~mm}\end{array}$ & Nylon & World & 0.0000 & 0.0000 & 6.4000 \\
\hline Disc & $\begin{array}{c}2.25 \mathrm{~cm} \\
\text { radius, } 3.08 \\
\text { mm height }\end{array}$ & $\begin{array}{c}\text { Stainless } \\
\text { Steel }\end{array}$ & World & 0.0000 & 0.0000 & 14.3400 \\
\hline $\begin{array}{c}\text { SOURCE } \\
\mathbf{z}_{0} \\
\end{array}$ & Loc & ted on the su & ace of th & lisc; $z_{0}=$ & $.88 \mathrm{~mm}$ & \\
\hline Mylar & $\begin{array}{c}17.9 \mathrm{~mm} \\
\text { radius; } 5 \mu \mathrm{m} \\
\text { height }\end{array}$ & Mylar & World & 0.0000 & 0.0000 & 15.8825 \\
\hline $\begin{array}{c}\text { Cell } \\
\text { Monolayer }\end{array}$ & $\begin{array}{c}17.9 \mathrm{~mm} \\
\text { radius; } 10 \mu \mathrm{m} \\
\text { height }\end{array}$ & $\begin{array}{l}\text { Nucleus; } \\
\text { Cytoplasm }\end{array}$ & World & 0.0000 & 0.0000 & 15.8900 \\
\hline Media & $\begin{array}{c}17.9 \mathrm{~mm} \\
\text { radius; } 1.5 \mathrm{~cm} \\
\text { height }\end{array}$ & $\begin{array}{c}\text { Water } \\
\text { equivalent }\end{array}$ & World & 0.0000 & 0.0000 & 23.3950 \\
\hline Sleeve & $\begin{array}{c}17.9-19.95 \\
\text { mm radius; } \\
29.6 \mathrm{~mm} \\
\text { height } \\
\end{array}$ & Polystyrene & World & 0.0000 & 0.0000 & 27.6000 \\
\hline
\end{tabular}

Table 2-8: Solid, logical and physical volume details for the volumes described by the ARES model. The World volume is centred on the origin, and the rest of the physical volumes are placed with reference to the World origin. The overall cell layer is displayed, not the individual cell components.

\subsubsection{Physics List (PL)}

The PL was adapted from the MB code with only a minor modification. The list includes all particle and process definitions for low-energy physics functions, a standard electromagnetic events package and particle cuts production.

For the ARES simulations, the production cuts were set to $10 \mathrm{~nm}$ for all areas of the simulation. Note that the value of the cut, as a distance can be converted to 
the energy required to travel in a step of that distance in whichever volume the particle is in. This is typical for GEANT4 simulations.

\subsubsection{Primary Generator}

The Primary Generator (PG) was rewritten for the ARES set up. The ARES PG consisted of an isotropic disc source, located at the upper surface of the stainless steel dish $\left(z_{0}\right)$. The activity of the source was controlled by the number of events generated. The events were generated as 1 alpha particle with origin and trajectories described by Equations 18 and 19. To speed up the simulations and increase computing efficiency, alpha particles travelling into the stainless steel base were ignored. Since only the alpha particles travelling into the upper hemisphere were tracked, the surface emission rate was used to calculate dose. A separate simulation was run to investigate the effects of backscattered particles, incident on the stainless steel base.

$$
\begin{array}{ll}
z_{0}=15.88 m m & \text { Equation } 18(a) \\
x_{o}=- \text { sizeMax }<r n_{\text {limit }}<\text { sizeMax } & \text { Equation } 18(\mathrm{~b}) \\
y_{0}=- \text { sizeMax }<r n_{\text {limit }}<\text { sizeMax } & \text { Equation } 18(\mathrm{c})
\end{array}
$$

As long as:

$$
\sqrt{\left(x_{o}^{2}+y_{o}^{2}\right)} \leq \operatorname{sizeMax}
$$

Where: $\quad\left(x_{0}, y_{0}, z_{o}\right)=$ co-ordinates of the particle origin sizeMax $=$ the active radius of the disc $(2.25 \mathrm{~cm})$ $r n_{\text {limit }}=$ random number generated within the given limits 


$$
\begin{aligned}
& \cos \theta=2 \cdot r n_{i}-1 \\
& \sin \theta=\sqrt{1-\cos ^{2} \theta} \\
& \varphi=r n_{j} \cdot 2 \pi \\
& x^{\prime}=\sin \theta \cos \varphi \\
& y^{\prime}=\sin \theta \sin \varphi \\
& z^{\prime}=\cos \theta
\end{aligned}
$$

Equation 19 (a)

Equation 19 (b)

Equation 19 (c)

Equation 19 (d)

Equation 19 (e)

Equation 19 (f)

Where: $\quad \theta, \varphi=$ zenith and azimuth angles respectively

$\left(x^{\prime}, y^{\prime}, z^{\prime}\right)=$ vertex of the initial particle trajectory $r n_{i}, r n_{j}=$ uniform random numbers generated between 0 and 1

The energy of the primary alpha particle was always set to the weighted mean energy of the ${ }^{241} \mathrm{Am}$ alpha emissions, $5.48 \mathrm{MeV}$.

\subsubsection{Run, Event, and Stepping Actions}

For each new simulation, the absorbed dose to the nucleus was reset to 0 in the run action instructions. The random number generator status was also saved in case a simulation had to be restarted.

The dose to the nucleus calculations were described in the event action file, to be totalled for each individual alpha particle generated. After every event, the dose to the nucleus was sent to an output file (described in Section 2.5.7).

The stepping action file calculated the dose to the nucleus for every step the particle took, as well as the range of the particle. The details of where the energy 
was deposited during each step ( $L_{\text {Energy deposition }}$ ) was described in the stepping action file (Equation 20).

$$
\vec{L}_{\text {Energy deposition }}=\vec{L}_{\text {preStep }}+\left(\vec{L}_{\text {preStep }}-\vec{L}_{\text {postStep }}\right) \cdot r n
$$

Equation 20

Where: $\quad \vec{L}_{\text {prestep }}=$ particle location before the step was taken

$\vec{L}_{\text {postStep }}=$ particle location after the step was taken

$r n=$ uniform random number generated between 0 and 1

In this manner, the energy lost during the step was randomly deposited somewhere along the step length.

\subsubsection{Output}

The output files generated by the simulation were a summary of the dose delivered to the nucleus of a cell by each alpha particle (dose.txt), the range that each alpha particle travelled (range.txt) and the origin of each alpha particle (beamPosition.txt). After every alpha particle, the data was summarized in each of these files.

The data in the dose file was used to calculate the overall dose rate of the ARES. The average dose to nuclei from each alpha particle was averaged, and then the dose rate calculated from Equation 21. 


$$
\dot{D}\left(\frac{G y}{h}\right)=\bar{D}\left(\frac{G y}{\alpha}\right) \cdot S E\left(\frac{\alpha}{\min }\right) \cdot 60\left(\frac{m i n}{h}\right) \cdot \varepsilon_{P}
$$

\section{Equation 21}

Where: $\quad \dot{D}\left(\frac{G y}{h}\right)=$ dose rate to nuclei of the ARES

$\bar{D}\left(\frac{G y}{\alpha}\right)=$ mean simulated dose from one alpha particle striking the monolayer of cells

$S E\left(\frac{\alpha}{\min }\right)=$ surface emission rate (Table 2-2)

$\varepsilon_{P}=$ emission probability of an alpha particle of a given energy

Since the weighted mean energy of the ${ }^{241} \mathrm{Am}$ alpha particles (Table 2-1) was used in the simulation, $\varepsilon_{P}$ was set to 1 .

The range data were used to generate a histogram in order to verify that the range of the alpha particles were as expected, based upon the independent SRIM2008 simulation.

The beam position data were used to verify that the alpha particle origins and trajectories were modelling those of an isotropic disc source. The origin vectors were plotted in an $(x, y)$ scatter plot, since the $z$ remained constant (as the surface of the disc). 


\section{CHAPTER 3. RESULTS}

\subsection{Sources}

\subsubsection{Alpha Sources}

A source of alpha radiation, in the form of six ${ }^{241} \mathrm{Am}$ electroplated stainless steel discs were procured with NIST calibrated activities ranging from 56.68 to 71.34 $\mathrm{kBq}$ and SE rates ranging from $1.69 \times 10^{6}$ to $2.12 \times 10^{6}$ emissions per minute. These discs provide an isotropic source of alpha particles, with a long half life (432 years) and a long working life (recommended 2 years). Over the course of 1 year, the activity of the source will decrease by $0.16 \%$. The most probable energy of the ${ }^{241} \mathrm{Am}$ alpha particle is $5.48 \mathrm{MeV}$, which is comparable to that of ${ }^{222} \mathrm{Rn}$ at $5.59 \mathrm{MeV}$.

The sources can be sterilized and are maintained in a customized nylon holder. The sources can be placed directly in the incubator for extended exposure times in order to maintain appropriate cell culture conditions.

\subsection{Dishes}

\subsubsection{Transmission of Alpha Particles}

SRIM2008 was used to calculated the transmission of alpha particles through the base of the MD and into the monolayer of cells (Figure 3-1). The MD, with its thin $(5.0 \mu \mathrm{m})$ Mylar base, allowed the transmission of $100 \%$ of the incident alpha particles. Only at the most oblique angles was it possible that the alpha particle would miss the cell monolayer. As expected, the alpha particle tracks were very linear, with a no more than $5 \mu \mathrm{m}$ scatter in the lateral axis. 


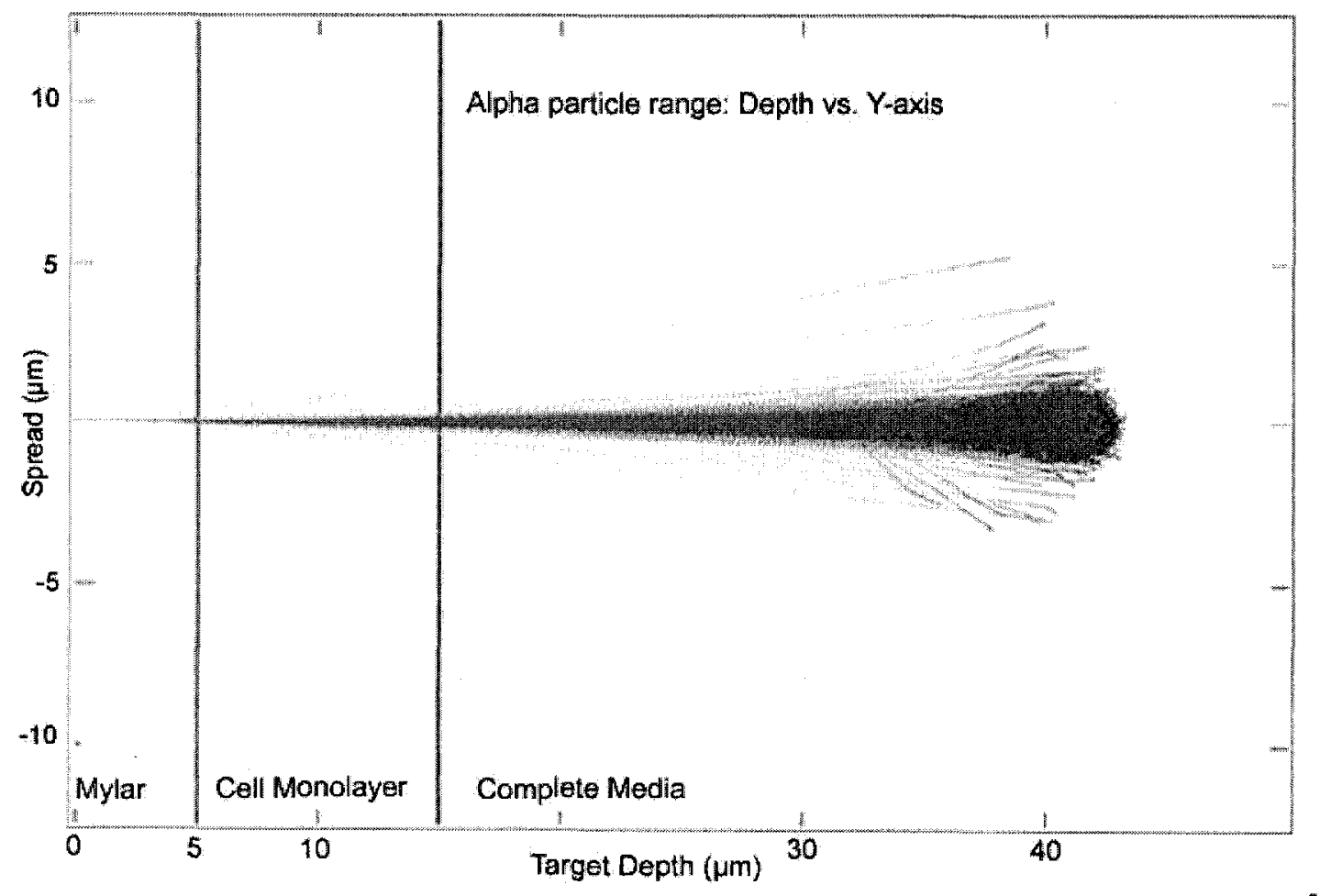

Figure 3-1: SRIM2008 simulation of the transmission of ten thousand 5.48 $\mathrm{MeV}$ alpha particles (incident at $0^{\circ}$ ) through $5 \mu \mathrm{m}$ of Mylar, $10 \mu \mathrm{m}$ of a cell monolayer and stopping within the media. The longitudinal range of the ions was $41.9 \pm 0.5 \mu \mathrm{m}$ with a lateral projection of up to $0.5 \pm 0.1 \mu \mathrm{m}$. 


\subsubsection{Sterilization and Cell Culture}

The dish components were sterilizable in an autoclave at $121^{\circ} \mathrm{C}$ for 25 minutes. The dishes, put together in a biohazard hood, could then be kept until required.

With only one layer of Mylar for a base, the dishes were susceptible to leaking if the membrane was compromised. Using two layers of Mylar (for a total thickness of $5.0 \mu \mathrm{m}$ ), the dishes proved to be much more robust, and did not leak throughout the course of the experiments.

The dishes were compared to typical cell culture dishes and proved to be an acceptable dish to support cell growth and culture. Growth curves were performed on two different cell lines, comparing growth on the MD to growth in a typical cell culture dish (6WP), with a collagen coating (C) and without a collagen coating (NC), and at different seeding densities. The results of the growth curves are shown in Figures 3-2, 3-3, 3-4 and 3-5.

From Figure 3-2, it is clear that the growth of the U87-MGs was improved with the use of collagen (the dashed line). It was visually observed under a microscope that the U87-MG cell growth was irregular and the cells tended to clump together, forming small tumours, rather than spread out in a monolayer. During cell culture, these tumours were more likely to slough off, skewing the counting results. There are two points missing from the MD with NC curve; these samples were discarded because the Mylar membrane of the dish had been compromised.

The collagen growth curves (Figure 3-2) were done independently from the seeding density growth curves (Figure 3-3). The 6WP conditions for both figures were the same in each experiment, as were the conditions for the growth on the Mylar with collagen (MD (C)) and the growth on the Mylar at $1 x$ the seeding 
density (MD 1x SD). The data is different, but for these same culture conditions, a similar growth pattern can be noted between the two experiments.

Despite the use of a collagen coating on the Mylar for the seeding density experiments, the growth on the Mylar was not improved. Floating cell debris was observed under the microscope, and the U87-MG cells continued to clump. At $3 \times \mathrm{SD}$, the cells grew slightly better, but still clumped into tumours before spreading out into a confluent monolayer. After about 40 hours, there were too many tumours, and a significant fraction of the cells sloughed off during cell culture. This accounts for the large drop in the growth curve of $M D$ at $3 \times \mathrm{SD}$ (dotted line).

The A-549s grew very well on the Mylar. When viewed under the microscope, cells were spread out along the surface of the dishes in a fairly uniform monolayer, with no clumps. The growth of the A-549s were compared with and without a collagen coating on the Mylar membrane (Figure 3-4), and the cells seemed to grow quite well without the collagen. Under observation, the cells continued to grow in a monolayer, even when highly confluent. At 100 hours, the counts had large error bars, although nothing unusual was observed under the microscope. After approximately 100 hours, the growth curves were stopped, even though the plateau phase had not yet been observed. 
Growth curve comparing the growth of U87-MGs on a 6WP and on MDs with collagen (C) and without (NC)

a collagen coating

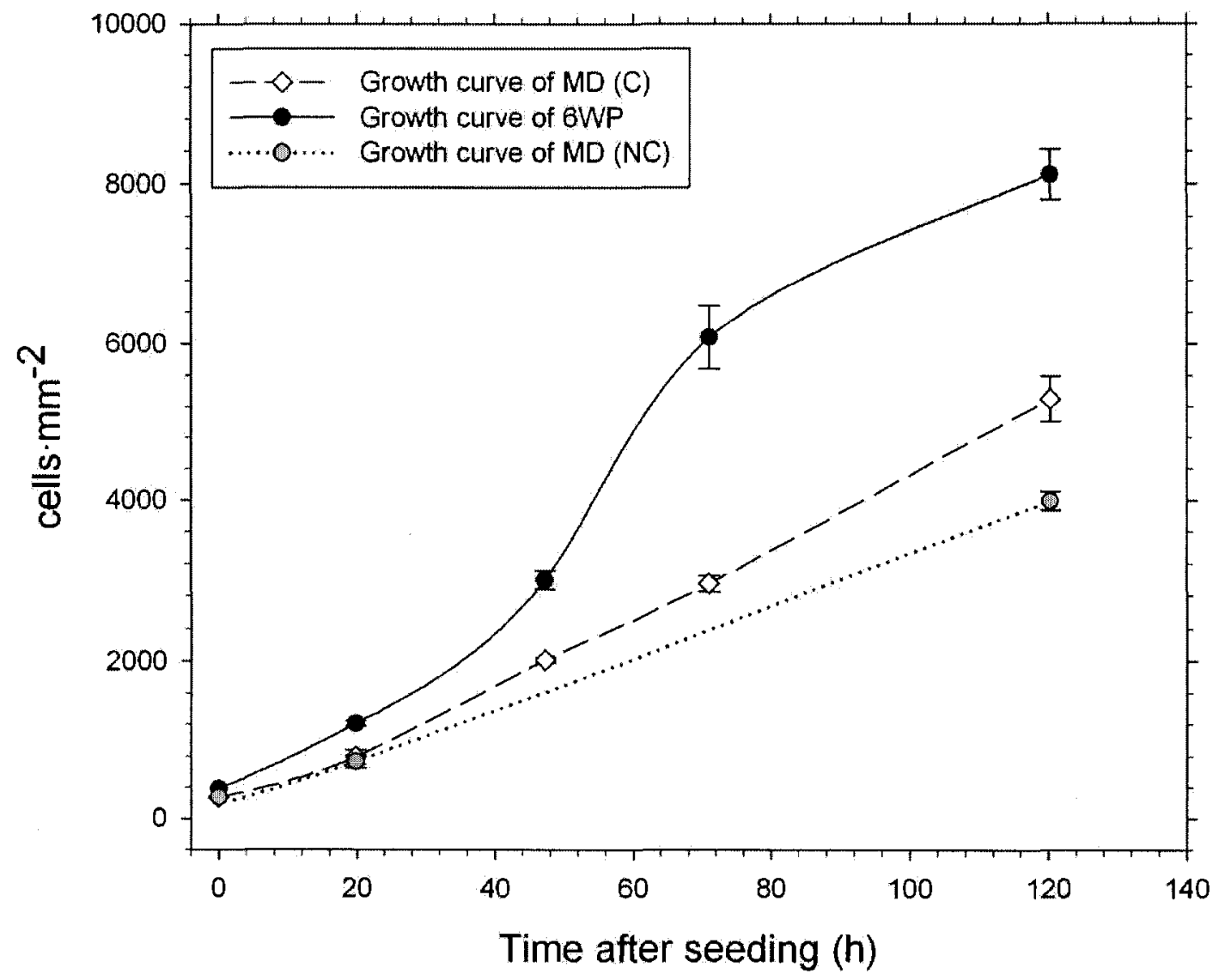

Figure 3-2: Growth Curve of U87-MG cells on 6WP and MDs, with and without collagen. The trendlines are curved splines to illustrate the general trend of the plots; they are not regression fits. The $x$ axis error bars were less than $1 \%$ and are therefore not illustrated on the Figure. 
Growth curve comparing the growth of U87-MGs on a 6WP and MDs at different initial seeding densities

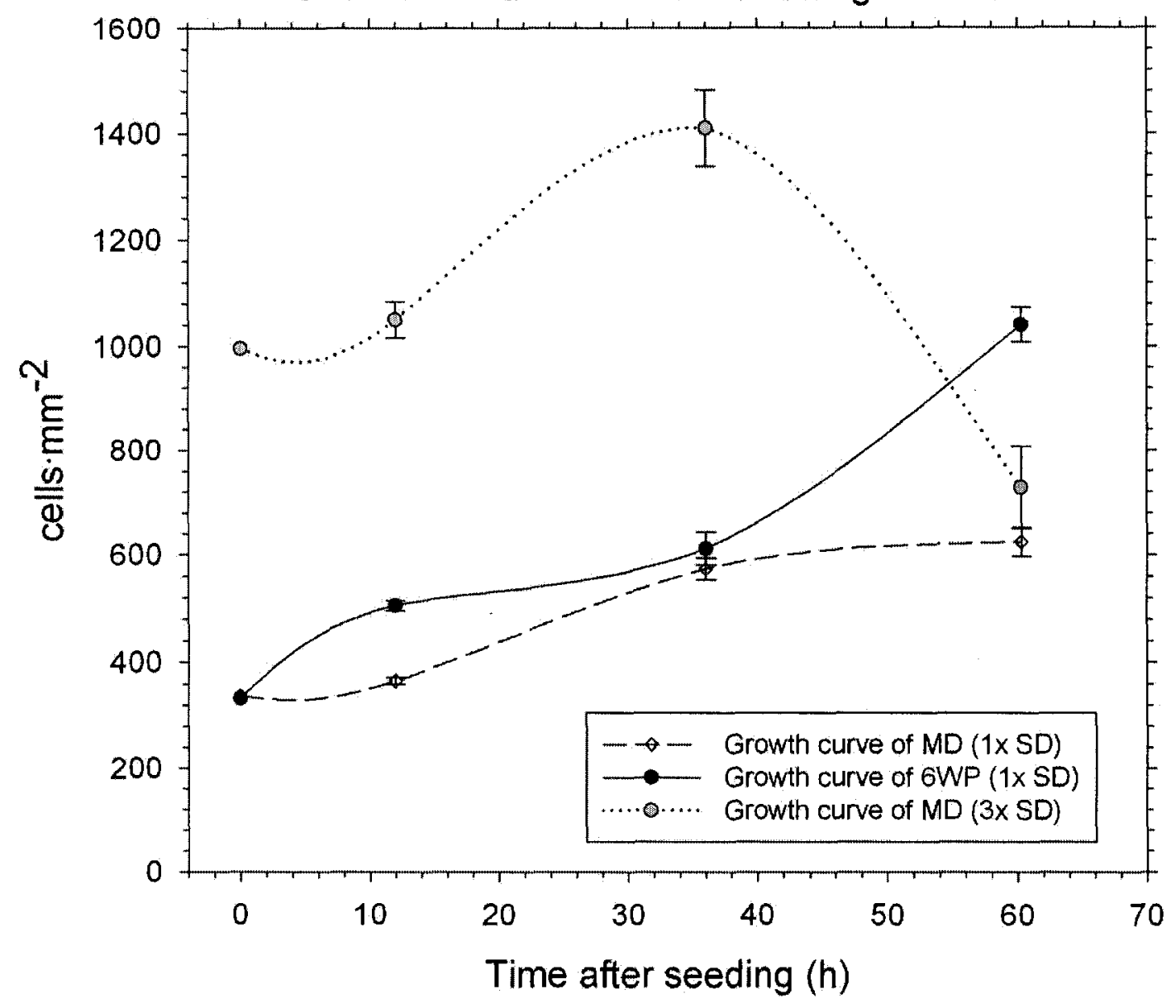

Figure 3-3: Growth Curve of U87-MG cells on 6WP and MDs, at different seeding densities. The MDs were seeded at one times the recommended seeding density (1x SD) and at three times the recommended seeding density $(3 x \mathrm{SD})$. The trendlines are curved splines to illustrate the general trend of the plots; they are not regression fits. The $x$-axis error bars were less than $1 \%$ and are therefore not illustrated on the Figure. 
Growth curve comparing the growth of A-549s on a 6WP

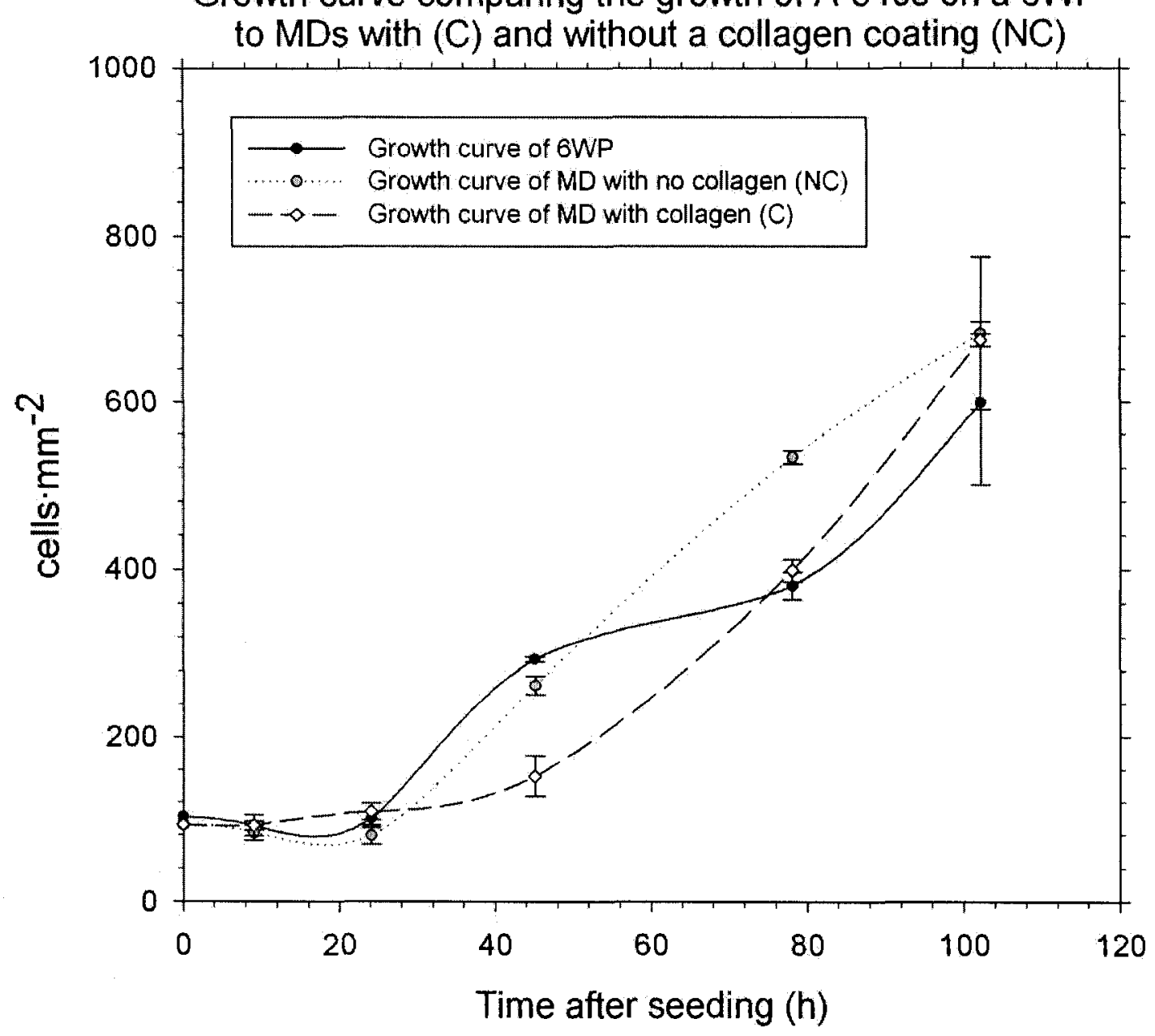

Figure 3-4: Growth Curve of A-549 cells on 6WP and MDs, with and without collagen. The trendlines are curved splines to illustrate the general trend of the plots; they are not regression fits. The $x$-axis error bars were less than $1 \%$ and are therefore not illustrated on the Figure. 
Growth curve comparing the growth of A-549s on a 6WP and on MDs at different initial seeding densities

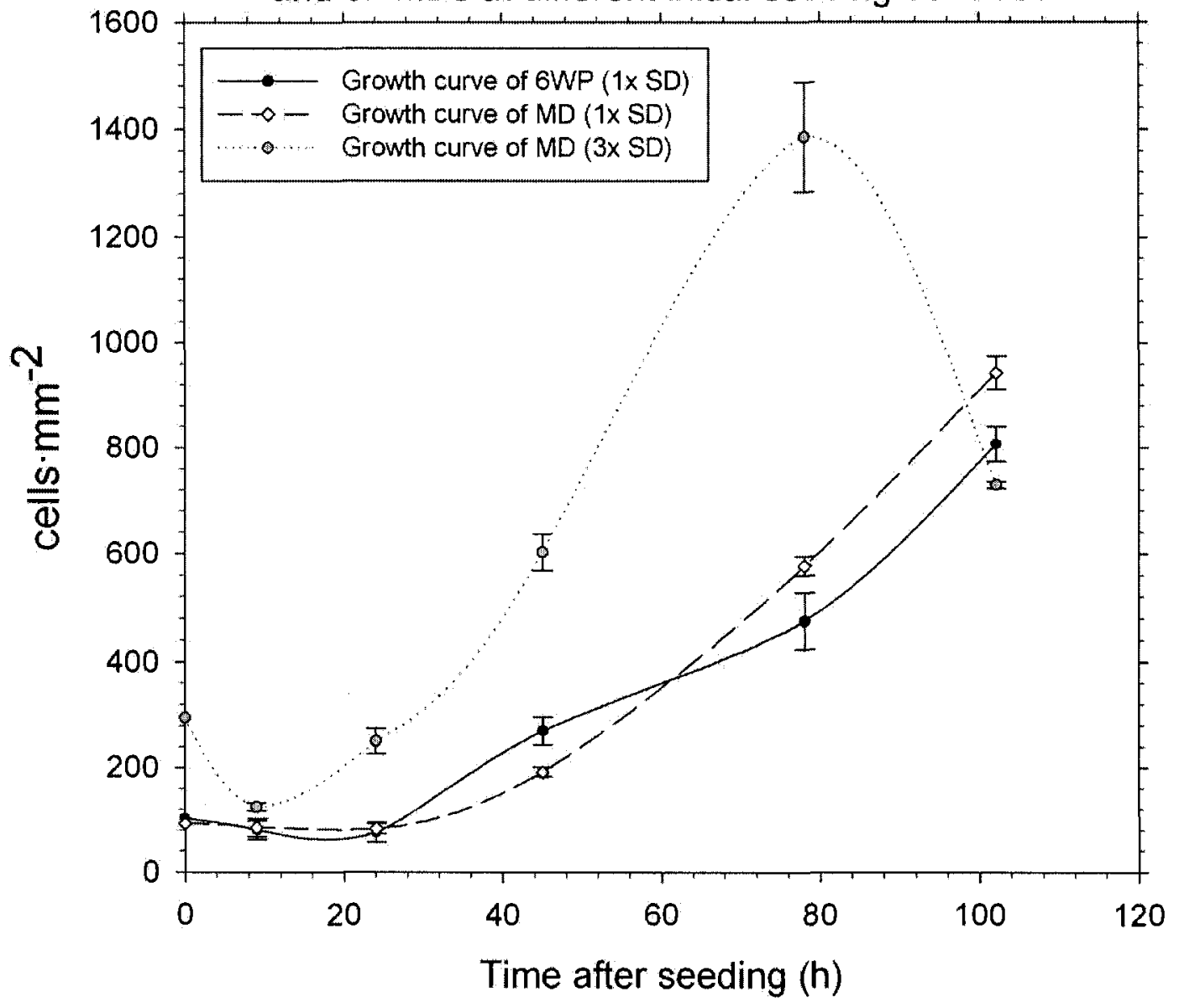

Figure 3-5: Growth Curve of A-549 cells on 6WP and MDs, at different seeding densities. The MDs were seeded at one times the recommended seeding density (1x SD) and at three times the recommended seeding density $(3 \times \mathrm{SD})$. The trendlines are curved splines to illustrate the general trend of the plots; they are not regression fits. The $x$-axis error bars were less than $1 \%$ and are therefore not illustrated on the figure. 
When the seeding densities were compared for the A-549s (Figure 3-5), the cells seeded at three times the seeding density ( $3 \times \mathrm{SD}$, the dotted line) grew very well. Data from the 6WP (solid line) and one times the seeding density followed a similar growth pattern as they did under the same conditions in Figure 3-4 (6WP and MD (NC)). The experiments were run independently and therefore the data are not exactly the same. Around 80 hours, the 3x SD curve peaks and then drops off rapidly; this is due to the cells, seeded at such a high density, becoming over grown and beginning to slough off during cell culture.

In both Figures 3-4 and 3-5, a lag phase is visible, lasting approximately 24 hours. The A-549s were solely used for the clonogenic assays; the Mylar dishes were left without a collagen coating, and were seeded at $3 \times$ SD. The dishes were seeded at $3 \mathrm{x}$ SD since they became confluent quickly and there was no need to feed the cells before irradiating. The cells were irradiated 48 hours after seeding, to ensure a high number of cells, while remaining in the exponential growth phase of the growth curves.

\subsection{Dosimetry}

The ARES was simulated to have a dose rate to the nucleus of $0.42 \pm 0.03 \mathrm{~Gy} \mathrm{hr}{ }^{-1}$ using a GEANT4 simulation, adapted from the MB source code. The code detailed the geometry of 1 MD on a disc source, set within a nylon holder. The dish was modeled to contain a monolayer of approximately 13 million cells, with the nucleus making up $64 \%$ of the cell volume, and a nucleus density of $1.3 \mathrm{~g} \mathrm{~cm}^{-}$ 3. The cell nucleus was defined as the sensitive detector area, and the dose was calculated as it was deposited along the alpha tracks within the nucleus of each cell. The dose was not considered outside of the regions of interest.

A simulation of $5 \times 10^{5}$ initial particles was run to ensure a standard deviation of the mean of $2 \%$. The resulting dose rate was $0.42 \pm 0.03 \mathrm{~Gy}^{\mathrm{h}} \mathrm{hr}^{-1}$ (or $(7.0 \pm 0.5) \mathrm{x}$ 
$\left.10^{-3} \mathrm{~Gy} \mathrm{~min}^{-1}\right)$. Using this dose rate, the time of exposure was converted to an absorbed dose (Table 3-1). The uncertainty on dose was calculated by Equation 22.

$$
\frac{\sigma_{D}}{D}=\sqrt{\frac{\sigma_{\dot{\dot{D}}}^{2}}{\dot{D}^{2}}+\frac{\sigma_{t}^{2}}{t^{2}}}
$$

Where: $\quad t=$ time of exposure $(\mathrm{min})$

$\sigma_{t}=$ uncertainty on the time of exposure

$\dot{D}=$ dose rate $\left(\right.$ Gy $\left.\mathrm{min}^{-1}\right)$

$\sigma_{\dot{D}}=$ uncertainty on the dose rate

\begin{tabular}{|r|r|r|}
\hline $\begin{array}{c}\text { Time of } \\
\text { exposure } \\
\text { (min) } \\
\pm 0.5\end{array}$ & $\begin{array}{c}\text { Absorbed } \\
\text { Dose } \\
\text { (Gy) }\end{array}$ & $\begin{array}{c}\text { Error on } \\
\text { Dose } \\
\text { (Gy) }\end{array}$ \\
\hline 0.0 & 0.000 & 0.003 \\
\hline 5.0 & 0.035 & 0.004 \\
\hline 30.0 & 0.21 & 0.01 \\
\hline 60.0 & 0.42 & 0.01 \\
\hline 90.0 & 0.63 & 0.02 \\
\hline 120.0 & 0.84 & 0.02 \\
\hline 240.0 & 1.68 & 0.04 \\
\hline
\end{tabular}

Table 3-1: Conversion of the time of exposure to an absorbed dose with an uncertainty on dose calculated by Equation 22 .

The above dose rate was calculated based upon the activity of the reference disc, disc number E6-513. Since each disc had a slightly different activity, the dose rates were calculated for each disc based upon their individual activities (Table 32). 


\begin{tabular}{|l|r|r|r|}
\hline $\begin{array}{c}\text { Disc } \\
\text { Number }\end{array}$ & $\begin{array}{c}\text { Activity } \\
(\mathrm{kBq})\end{array}$ & $\begin{array}{r}\text { Dose rate } \\
\left(\mathrm{Gy} \mathrm{hr} \mathrm{r}^{-1}\right)\end{array}$ & $\begin{array}{c}\% \\
\text { difference }\end{array}$ \\
\hline E6-513 & 68.04 & 0.42 & 0.0 \\
\hline E9-881 & 71.34 & 0.44 & -4.9 \\
\hline E9-882 & 67.34 & 0.42 & 1.0 \\
\hline E9-883 & 62.01 & 0.38 & 8.9 \\
\hline E9-884 & 56.68 & 0.35 & 16.7 \\
\hline E9-885 & 69.63 & 0.43 & -2.3 \\
\hline
\end{tabular}

Table 3-2: Comparison of dose rates between the different ${ }^{241} \mathrm{Am}$ discs. The percentage difference uses disc number E6-513 as a reference disc.

The simulation output included details regarding the stopping range of each alpha particle. From the SRIM simulation (Figure 3-1), the alpha particles incident on the cells at $0^{\circ}$ come to rest at $41.9 \pm 0.5 \mu \mathrm{m}$. The range of the alpha particles along the $z$-axis from the ARES GEANT4 simulation, incident for angles $0^{\circ}$ to $90^{\circ}$ in a $2 \pi$ geometry, came to rest after $39.5 \pm 0.5 \mu \mathrm{m}$.

The initial trajectory angles of $1 \%$ of the alpha particles were plotted in a three dimensional scatter plot (Figure 3-6), to verify that the alpha particles were generated in an isotropic manner. Only $1 \%$ of the particles were plotted, since visually, all of the particles would have resulted in a solid sphere without any visible detail. While the source trajectories were isotropic, their origins were randomly spread out over the surface of the stainless steel disc, simulating an isotropic disc source. 


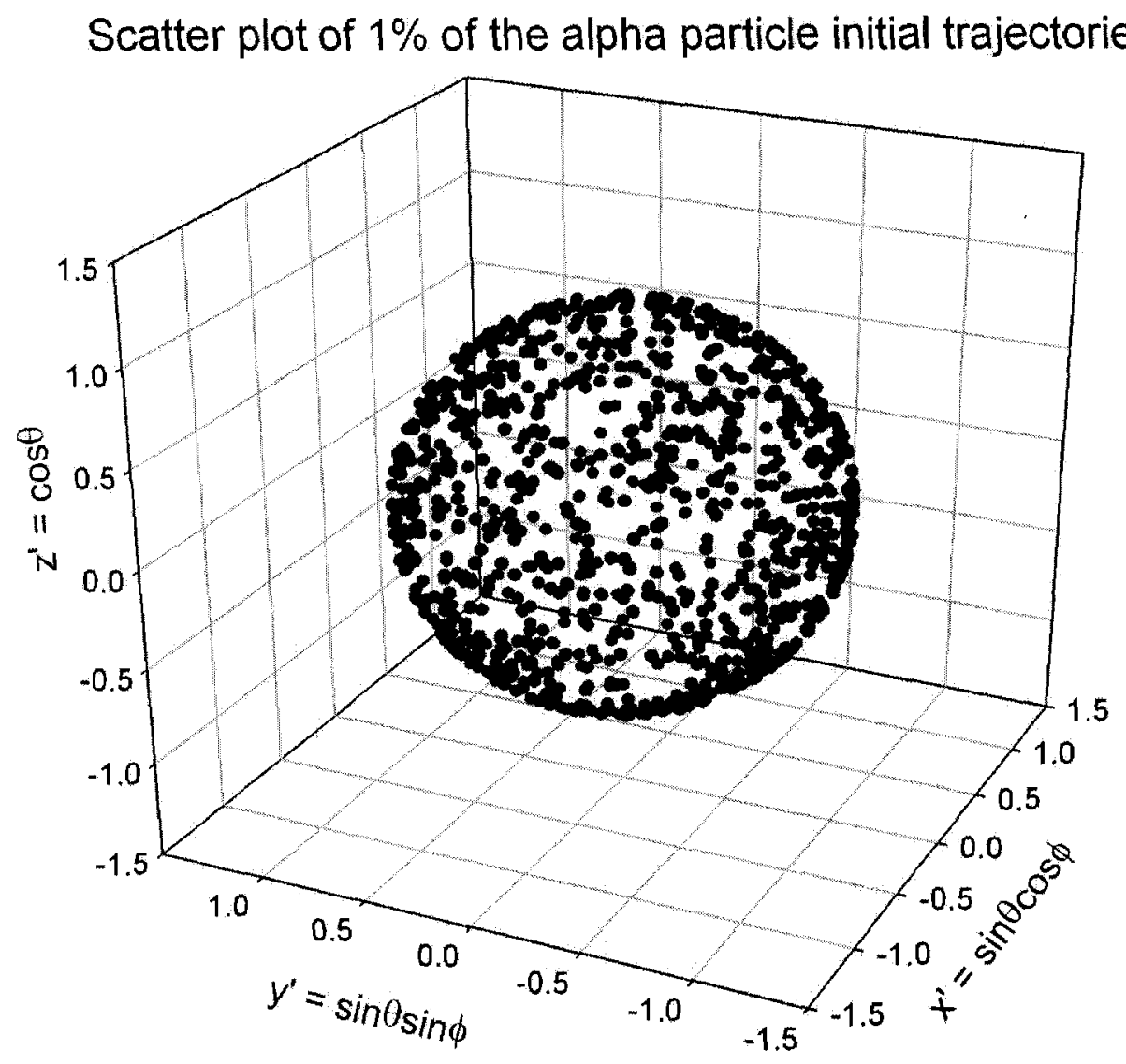

Figure 3-6: Three dimensional scatter plot of the initial trajectories of $1 \%$ of the alpha particles. Their initial trajectories were plotted in order to illustrate the isotropic nature of the alpha source. The vector origins were not plotted; these were randomly distributed over the surface of the stainless steel disc. 
The assumption that no dose was delivered from backscattered particles was verified by simulating ten thousand alpha particles incident towards the lower hemisphere only, towards the stainless steel base. None of the primary alpha particles were backscattered from the stainless steel to hit a cell.

\subsection{Survival Curves}

The exposure system was validated by performing survival curve experiments and comparing the calculated RBE values with that of similar experimental setups. Figure 3-7 compares the survival curves of gamma irradiation on the two different types of dishes, T25 and MD. Figure 3-8 compares two different types of radiation, gamma and alpha, on the same type of dish (MD). Figure 3-8 clearly demonstrate cell kill from exposure to the ${ }^{241} \mathrm{Am}$ discs.

The LQ fit of the alpha irradiated cells (Figure 3-8) is very good for the first 5 data points, but the higher doses pull away from the curve. The data was refit to account for a second population (Figure 3-9). The first five alpha dose points were fit as before, excluding the last two points. Then the last three points were fit, using an adjusted LQ model with an extra parameter to avoid forcing the curve through 1 for 0 Gy (Equation 17). This second fit for the alpha particles coincides very well with the data, and intercepts the surviving fraction axis for 0 Gy at $13.25 \%$.

The curve fitting details (alpha and beta values) are outlined in Table 3-3. The data were generated by the curve fitting software, and the standard errors are shown for all but the proposed alternate fit. 


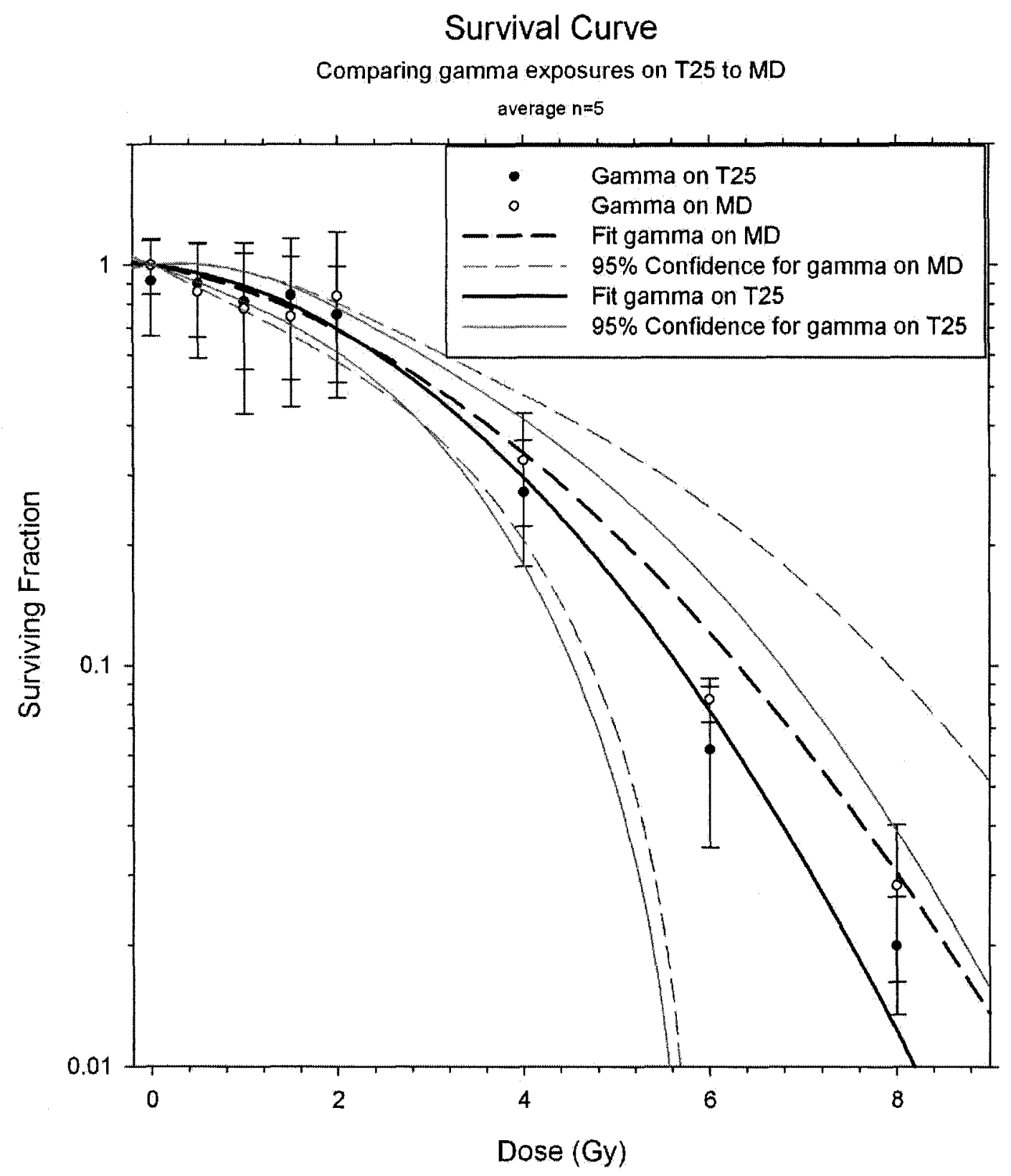

Figure 3-7: Survival curves, fit by LQ model, of gamma irradiation of A-549 cells in confluent T25s and confluent MDs. The surviving fraction error bars are calculated as the standard deviation of the mean. The dose error bars are $7 \%$ and are therefore not plotted. 


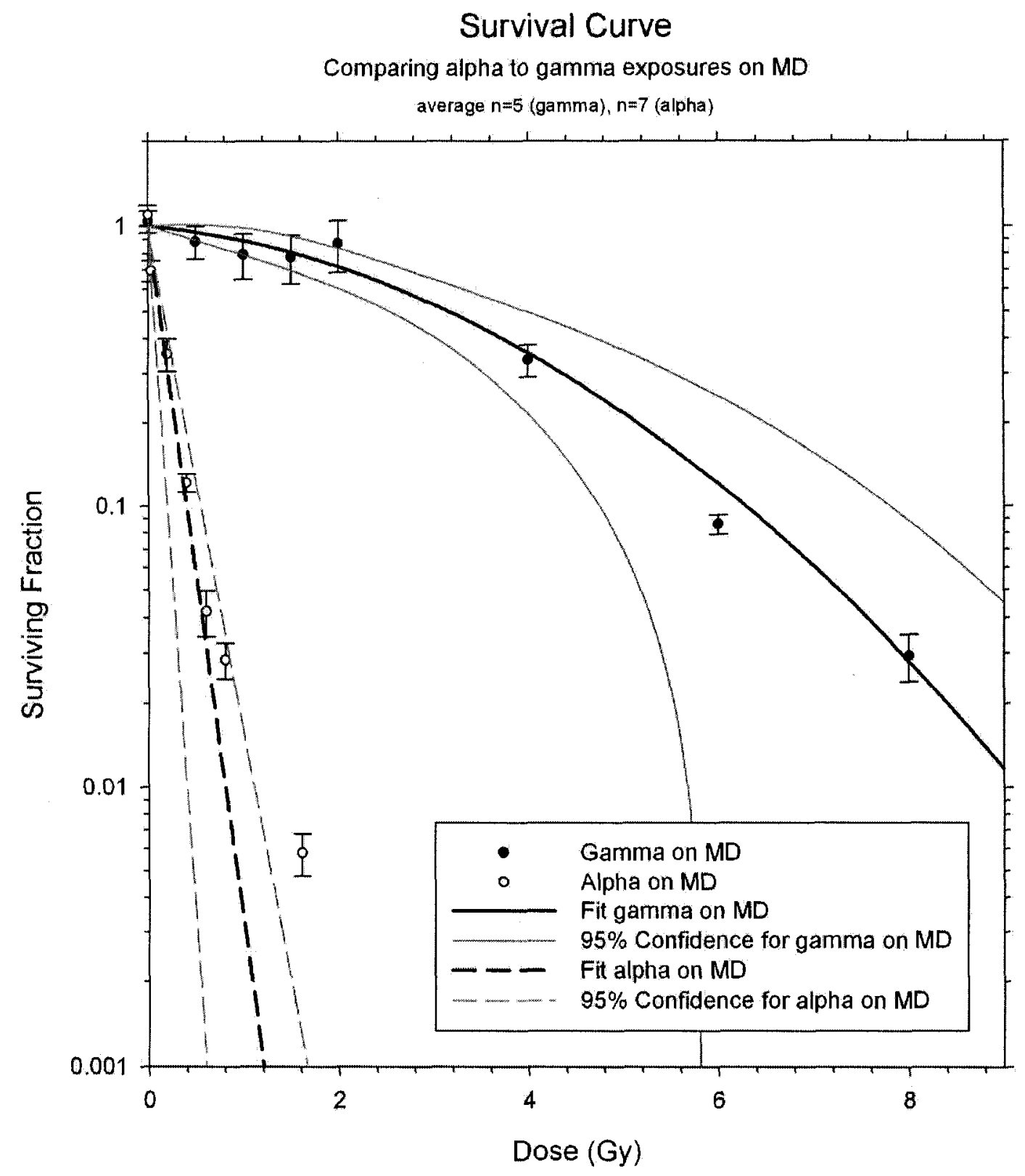

Figure 3-8: Survival curves, fit by LQ model, of gamma and alpha irradiation of A-549s in confluent MDs. The surviving fraction error bars are calculated as the standard deviation of the mean. The dose error bars are $7 \%$ and are therefore not plotted. 


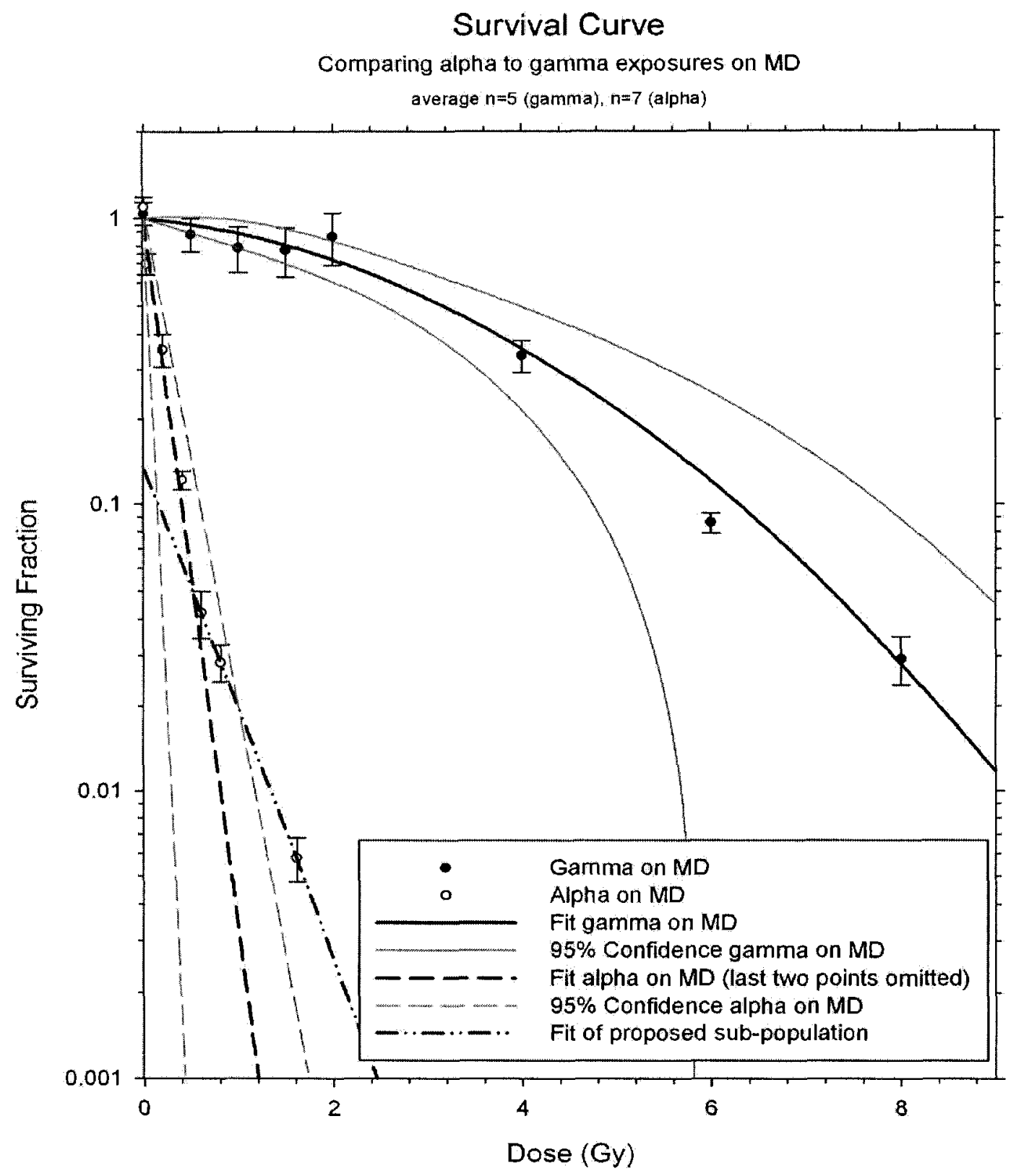

Figure 3-9: Survival curves, fit by LQ model, of gamma and alpha irradiation of A-549s in confluent MDs. The fit of the alpha irradiated dishes was done in two parts, with the last three data points fit to the adjusted LQ model (Equation 17). The surviving fraction error bars are calculated as the standard deviation of the mean. The dose error bars are $7 \%$ and are therefore not plotted. 


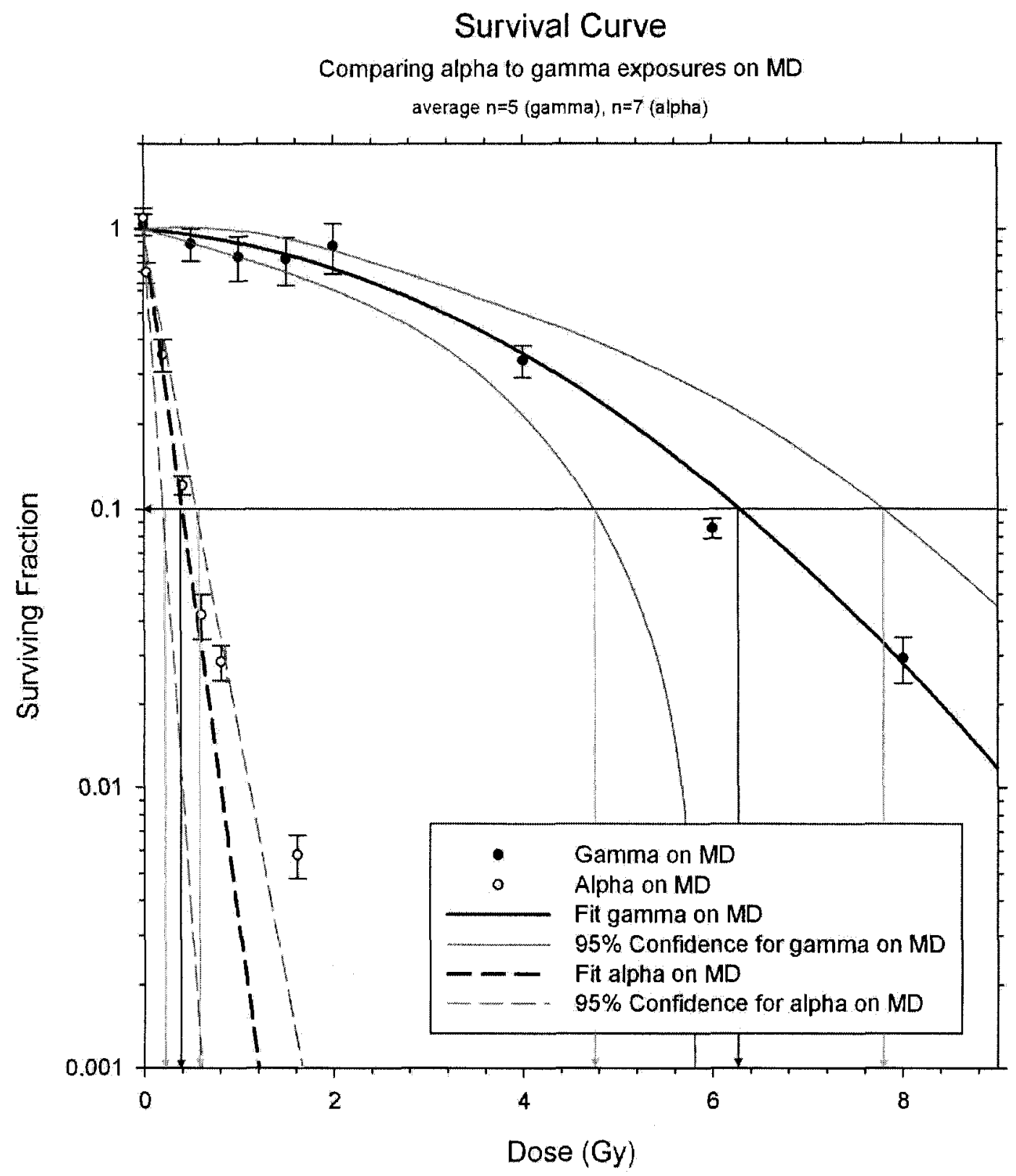

Figure 3-10: Alpha and gamma survival curves (Figure 3-8) with drop lines illustrating the dose points used for the RBE calculation. 


\begin{tabular}{|c|l|r|r|r|r|}
\hline $\begin{array}{c}\text { Figure } \\
\#\end{array}$ & Survival curve & $\alpha$ & $\begin{array}{r}\text { Std } \\
\text { Error }\end{array}$ & $\beta$ & $\begin{array}{r}\text { Std } \\
\text { Error }\end{array}$ \\
\hline Fig 3-7 & Gamma on MD & 0.10 & 0.06 & 0.04 & 0.02 \\
\hline Fig 3-7 & Gamma on T25 & 0.06 & 0.05 & 0.06 & 0.02 \\
\hline Fig 3-8 & Gamma on MD & 0.07 & 0.06 & 0.05 & 0.02 \\
\hline Fig 3-8 & Alpha on MD & 6.00 & 1.00 & 0.00 & 2.00 \\
\hline Fig 3-9 & Gamma on MD & 0.07 & 0.06 & 0.05 & 0.02 \\
\hline Fig 3-9 & Alpha on MD & 6.00 & 1.00 & 0.00 & 2.00 \\
\hline Fig 3-9 & $\begin{array}{c}\text { Alpha on MD } \\
\text { (alternate fit) }\end{array}$ & 1.87 & na & 0.05 & na \\
\hline
\end{tabular}

Table 3-3: Alpha and beta values from the fits of Figures 3-7 to 3-9. The values are taken from the reports generated by the graphing software (SigmaPlot 10.0). Since the proposed Alpha on MD (alternate fit) only had three variables and three parameters, there were no errors generated on the fit.

The RBE calculated by Equation 8, with the gamma irradiation as a reference and the alpha irradiation as a test, yields an RBE for $10 \%$ surviving fraction of $16 \pm 8$. The error on the RBE calculation was calculated according to Equation 23, with the errors on the doses taken from Figure 3-10, since the error on the fit of the curve is much larger than the error on the dose.

$$
\frac{\sigma_{R B E}}{R B E}=\sqrt{\left(\frac{\sigma_{D_{r e f}}}{D_{\text {ref }}}\right)^{2}+\left(\frac{\sigma_{D_{\text {test }}}}{D_{\text {test }}}\right)^{2}}
$$




\section{CHAPTER 4. DISCUSSION}

\subsection{Sources}

\subsubsection{Energy of the Sources}

Given that the weighted mean energy of ${ }^{241} \mathrm{Am}$ is $5.48 \mathrm{MeV}$, it can be considered an analogous source to ${ }^{222} \mathrm{Rn}$ and its progeny, which have an energy range of 5.5 to $7.7 \mathrm{MeV}$. The damage caused by alpha particles in this range of energies can be studied and the results taken to be analogous to what would be expected of ${ }^{222} \mathrm{Rn}$ exposure.

\subsubsection{Radioactive Decay over Time}

The change in activity of the sources was calculated and found to be less than one percent. This negligible change in activity over time means that experiments, which span a couple of weeks, are not significantly affected by a changing source activity. A correction factor was therefore not required.

\subsubsection{Protecting the Sources}

One of the biggest concerns with the electroplated disc sources is that they are considered an open source, with the radioactive ${ }^{241} \mathrm{Am}$ deposited directly on the surface of the stainless steel discs. These are considered to be delicate and care must be taken to avoid wiping, touching or scratching the surface of the discs [59], as this would remove radioactivity and the source would no longer be accurately calibrated.

A number of support systems were considered, that would allow the cells to be as close as possible to the surface of the source, without removing any of the ${ }^{241} \mathrm{Am}$. Such support systems often had the cells raised above the source, introducing an air gap. This is problematic for a few reasons. The height of the air gap would have to be kept constant over all the experiments to avoid 
introducing another source of uncertainty. Also, since alpha particles are easily stopped in most media, including air, energy would be lost to the air gap, and the dosimetry would be more complicated. It was decided that the Mylar dishes would be placed very gently, directly upon the discs.

In order to verify that the ${ }^{241} \mathrm{Am}$ was not being transferred to the Mylar during the course of an experiment, a test was done where a dish was placed upon a source for over 4 hours (the longest exposure time), and then removed. The Mylar membrane was then removed from the dish, and placed in a sample holder for a liquid scintillation measurement. The liquid scintillation measurement was performed by Gerry Moodie of the National Calibration Reference Centre for Bioassay (Radiation Protection Bureau, Health Canada). The results showed that there was no alpha particle contamination, with a minimum detection limit of $0.1 \mathrm{~Bq}$ gross alpha particles per membrane. Therefore with appropriate care to avoid scratching or rubbing the surface of the discs, the placement of the dishes upon the source was acceptable.

Spilling media on the surface was also important to avoid, since a build up of media would become a barrier on top of the source for the alpha particles to traverse.

The simple nature of the set-up, without complicated mechanics, allowed the sources to be placed directly in an incubation chamber with atmospheric conditions conducive to cell culture. Due to the lower dose-rate, this was important for the cells. Without the presence of a shutter, however, it was important to pay close attention to the time of exposure [49]. 


\subsection{Dishes}

\subsubsection{Fabrication}

The dishes were fairly simple to fabricate, but there were a few issues to note. Wrinkled Mylar or large air pockets would decrease the number of alpha particles transmitted to the cells causing the simulated dose rate to be over estimated. It was essential that the Mylar membranes were stretched tightly across the bottom opening of the plastic sleeve to avoid wrinkles and air pockets which could reduce the accuracy of the dosimetry.

In addition, testing the integrity of the Mylar membranes during handling was performed. It was found that if care was not taken, the membranes would begin to leak over time. Rougher handling entailed sliding the dish over surfaces, even smooth ones, and touching the membrane more than necessary. In order to minimize the likelihood of leaks, caution was taken to handle the Mylar by its cardboard holder and to always pick up the dish before moving it. Sliding of the dish along a surface was avoided. The membranes could also easily be punctured by sharp objects. This was most likely to occur when aspirating the media, PBS or trypsin-EDTA from the dish using the Pasteur pipettes. To avoid this type of puncture, the tip of the pipettes was placed slightly above the membrane along the lower surface of the plastic sleeve. This was sufficient to properly aspirate the dish without compromising the Mylar.

\subsubsection{Cost}

Given that a gamma exposure is normally performed in a T25 flask, this was used as a point of comparison for the cost of the MD. A single MD, consisting of the three piece plastic sleeve and two layers of Mylar sandwiched between them, cost $0.83 x$ the unit cost of a T25. The larger expense is the time it takes to fabricate the dish, which ranges up to at most a day if a coating of collagen is used, to as 
little as a few hours, including the autoclaving and cooling process. The dishes can be put together in batches, and large sets of dishes and Mylar can be sterilized well ahead of time, and kept in sealed containers for future use in order to minimize preparation time.

\subsubsection{Attenuation and Build-up}

The attenuation of the gamma irradiation through the plastic is not significant with respect to the intensity of the photon beam reaching the cell layer. The photons travel through sufficient material before reaching the cell layer (polystyrene, or polystyrene, air and media) to reach charged particle equilibrium.

\subsection{Cell Lines}

\subsubsection{Use of Immortalized Cells or Primary Cells}

Immortalized cells were used because they could be reliably cultured through generations (passages) without mutating. Primary cells are more difficult to work with, and it is not recommended to subculture them as many times. For the purpose of characterizing the ARES, immortalized cells, with quick doubling times, short lag phases and reliable growth characteristics were ideal.

\subsubsection{Use of Adherent Cells or Suspension Cells}

The ${ }^{241} \mathrm{Am}$ discs provided an isotropic source. For the dosimetry, the assumption was made that the cells formed a confluent monolayer along the bottom surface of the dishes. This assumption required the use of an adherent cell line for the ARES experiments.

Two immortalized, adherent cell lines were investigated; U87-MGs, which are human brain glioblastoma cells, and A-549s, which are human lung epithelial 
cells. The U87-MGs were long and thin, and they had a tendency to grow into small clumps of mini tumours rather than spread out over the surface of the dish. Before a confluent monolayer could be formed, the mini tumours would become too large and would be aspirated off the surface during the course of cell culture. The A-549s were more circular, and spread out to form a very confluent monolayer on the surface of the Mylar. When overgrown (highly confluent), the cells would become very tightly packed, but did not form any mini tumours.

The use of a collagen coating was also investigated, to facilitate cell growth in culture. Normal cell culture methods (trypsin, etc) were used without any problem, and the collagen did not interfere with the cellular response aside from tissue organization [60;61]. While collagen improved the growth of the U87-MGs slightly, it did not noticeably affect the growth of the A-549s. It is recommended that any new cell line should be characterized with and without the use of collagen before proceeding with further experiments.

Since the alpha particles have enough energy to traverse the cells and come to rest further into the complete media, there is a possibility for future experiments with suspension cells. The problem would be in the accuracy of the dosimetry. If the cells settled to the bottom of the dish quickly, relative to irradiation time, and settled in a homogeneous manner, the dose to a 'thickness' of cells could be calculated. In the meantime, for the current experiments, only adherent cell lines were examined, and a highly confluent, homogeneous cell line was used to characterize the system. The A-549s provided the most uniform monolayer cell culture with reliable growth and clumping of cells was non-existent. The cells were irradiated when they were very confluent and while still in the exponential growth phase, 48 hours after seeding. 


\subsection{Dosimetry}

\subsubsection{Monte Carlo Model}

The dosimetry of the ARES was simulated using the GEANT4 Monte Carlo toolkit. The ARES simulation, run with $5 \times 10^{5}$ primary events, had a statistical error on the dose rate of $2 \%$. The random number generator, having a period of 2 $x$ 1018, was more than capable of handling the ARES simulation without repeating the sequence of random numbers. The distribution of alpha particle track lengths was a source of variation in cell dose, which would be averaged out with increased statistical events.

The ARES model was adapted from an example, the CENBG Microbeam. The geometry of the model was completely rewritten to represent the ARES, and to remove unnecessary components from the Microbeam model. The geometry was modeled after only one source and one dish. Eventually the model could be expanded to include all six of the sources and dishes, but for the basic dosimetry, this was unnecessary. To improve the geometry of the model, the location of the cells and the location of the nucleus within the cells could have been randomized. The effect of orderly and systematic placement of the cells and nuclei is likely small, since the cells were modeled as a confluent monolayer. The probability of a nucleus being traversed by an alpha particle was still random.

The physics list was the same as the Microbeam list, and implemented all of the standard physics processes that could occur with low energy models; multiple scattering, electron, muon and low energy ionization, electron, muon and low energy bremsstrahlung production, positron annihilation, low energy photoelectric effect, gamma conversion, Rayleigh scattering, Compton scattering, low energy elastic scattering, alpha inelastic scatting and binary light ion reactions. All of the standard particle types and definitions were also included; 
bosons (gamma and optical photons), leptons (electrons and positrons) and baryons (ions and mesons).

The primary generator modeled an isotropic source, emitting alpha particles from the surface of a $45 \mathrm{~mm}$ diameter disc. Secondary radiation from weak gamma sources was not taken into account.

Variance reduction techniques were not implemented, since the complexity of the system was not overly taxing on the computational resources. The recommended variance reduction technique, which would be simplest to implement, would be the use of production cuts. In the areas of the geometry where the alpha particles were unlikely to reach, such as the World volume outside of the dish, the production cuts could be increased from $10 \mathrm{~nm}$, to improve computational efficiency.

\subsubsection{Alpha Particle Range}

The range of the alpha particles, simulated in both SRIM and GEANT4 differed slightly, at $41.9 \pm 0.5 \mu \mathrm{m}$ and $38.5 \pm 0.5 \mu \mathrm{m}$ respectively. The simulations differed in the extent of the geometric and primary event detail included. The SRIM data were calculated with infinite slabs of material (with varying thickness) and the alpha particles were incident on the material at $0^{\circ}$. The GEANT4 simulation included three dimensional geometric data, as well, the incident particles originated from an isotropic source. Nonetheless, some of the GEANT4 particles, incident at $90^{\circ}$ would have made it to the same range if that were the only discrepancy. The most likely source of the discrepancy is the material information included in the slab and volumes. There is some indication that SRIM is limited by not including crystal structure information [62]. 
For the range of alpha particles in the GEANT4 simulation, there is a noticeable interface effect at the boundary of the Mylar and the beginning of the cell monolayer. Alpha particles incident at oblique angles would have more Mylar to traverse and would be more likely to stop within the higher density material.

\subsubsection{Dose Rate}

The dose rate of the gamma cell irradiator was $(49 \pm 3) \mathrm{Gy} \mathrm{hr}^{-1}$, compared to the dose rate of the ARES, at $(0.42 \pm 0.03) \mathrm{Gy} \mathrm{hr}^{-1}$. The dose rate of the gamma irradiation was slightly more than 100 times that of the alpha irradiation. While the dose rate does affect the shape of a survival curve, the effect is minimal when using high LET radiation where the majority of DSBs are caused by a single radiation track (mode 1 killing) and are not dependent upon the dose rate [43]. Other published set-ups had dose rates which ranged from 0.4 to $1400 \mathrm{~Gy} \mathrm{hr} \mathrm{hr}^{-1}$ [43;48-52]. These dose rates are highly dependent upon the activity of the source (with the maximum activity being $1.3 \mathrm{GBq}$ ), as well as the experimental set up. Some have gas filled chambers, collimators, rotating stages and variable heights (to adjust the dose rate) whereas the ARES set up is quite simplified, more closely resembling the isotropic nature of exposure to environmental radiation.

In order to increase the alpha dose rate, the cell monolayer could be moved further away from the source and closer to the Bragg peak. This would require caution as the closer the cells get to the Bragg peak, the more the dosimetry depends upon the slope of the peak, which changes dramatically within $5 \mu \mathrm{m}$. The size of the cells is on the same scale, roughly $10 \mu \mathrm{m}$ thick. Furthermore, a low dose gamma irradiator could be used to provide a more comparable dose rate between alpha and gamma irradiations.

Since the activity of the discs varied, the dose rates varied for each disc. Again, the difference in dose rates between the discs is not thought to be an important 
source of experimental variation, since mode 1 killing dominates the cause of DSBs. The difference in dose rates was taken into account by adjusting the time of exposure by a conversion coefficient (Equation 11).

\subsection{Cell Damage}

From the cell survival curves, it is clear that the ARES discs are delivering a significant amount of dose to the irradiated cells. The ARES calculated RBE value of $16 \pm 8$ for $10 \%$ survival is compared to an RBE of 9.9 (no error reported) for $10 \%$ survival for ${ }^{210}$ Po irradiated bovine endothelial cells [47].

The alpha irradiated curve also demonstrates an interesting trend at higher dose rates; the surviving fractions at the highest and second highest dose points do not fit the LQ curve as expected. A proposed alternative is the possibility of a radioresistant sub-population. When a second LQ fit is plotted, for the last points only, and extrapolated back to the axis for $0 \mathrm{~Gy}$, there is a $13.25 \%$ fraction which could be radioresistant.

There is some debate that there could be an adaptive response to radiation [63]; with induced radioresistance after initial exposure to low dose radiation. Since the higher doses are exposed for a long exposure time, 120 and 240 minutes, this could be evidence of an adaptive response. Further investigation, at longer exposures, and more intermittent dose points, would be required to investigate the validity of these theories.

Another issue to consider is the edge effects. The ring of cells along the edge of the MD are exposed to a more limited source of radiation, since half of the solid angle is shielded by the polystyrene material of the MD. This implies that the cells along the edge of the surface are exposed to a lower and hence overestimated dose, and thus they would have a higher surviving fraction than 
expected. From the proposed alternate fit of the alpha exposures, it appears that this sub-population is approximately $13 \%$ of the irradiated cells. While this might account for some cells being exposed to less dose, it is unlikely that $13 \%$ of the area of the dish (or roughly 1.7 million cells) were affected by edge effects. 


\section{CHAPTER 5. CONCLUSION}

\subsection{Functioning Alpha Exposure System}

The design and fabrication of this system included the calibration and optimization of the appropriate sources, dishes and related dosimetry. While care must be taken with the sources and the MD, the system is efficient and easy to use and maintain.

The sources have activities and energies which provide a reasonable dose-rate to the cell cultures. The energy of the alpha particles is similar to those of other common alpha particle emitters, particularly ${ }^{222} \mathrm{Rn}$, such that the experimental results can be generalized to other isotopes. The half-lives are long enough that the dose-rate does not perceptively change over the course of an experiment.

The dishes are comparable in size, cost and ease of use to regular culture dishes. The thinness of the Mylar is such that almost all of the alpha particles are transmitted to the monolayer of cells. The Mylar is also sufficiently firm to support the growth and culture of the cells. It also does not affect the method of cell culture.

The dosimetry, modeled in GEANT4, simulated a dose rate of $0.42 \pm 0.03 \mathrm{~Gy}^{\mathrm{hr}^{-1}}$. $^{-}$ The model accounts for the geometry of the dishes, the isotropic nature of the source and the physical processes which occur.

The system was verified by performing several clonogenic assays, and comparing alpha and gamma irradiation of an immortalized adherent cell line. The resulting $\mathrm{RBE}$ of $16 \pm 8$ is comparable to other alpha radiation systems. 


\subsection{Future Research}

Further work can be done to fine tune the modeling for the dosimetry calculations. The cell models are simplified and a more detailed model might include spacing from a less confluent dish. The model could also be adapted to simulate a slightly modified ARES which would include a thicker layer of Mylar. By increasing the thickness of the Mylar, the cells would be closer to the Bragg peak of the alpha particle trajectories and thus the dose rate would be increased. Dose rate experiments could be done to compare the effects of low dose rate and high dose rate alpha particle exposures.

Furthermore, the gamma system should also be modelled with a MC simulation, in order to calculate dose to the nucleus of the cell. In this manner, the RBE calculation comparing the doses between the alpha and gamma exposure systems would be more accurate.

A future model might also investigate dose to a suspension type of cell, such as lymphocytes (blood) which are of interest to biological dosimetry. An improved model could model the energy spectrum of the alpha source, and have the energy emissions weighted by the emission probabilities of the spectrum.

Cell kill is not the only result, or even the major result, of an ionizing radiation dose. Further investigation of the mutations and transformations are required to understand the biological effects of high-LET radiation. Using the ARES, experiments can be done to investigate the LET effect on chromosome damage, gene expression, and protein expression. These end-points would be of interest for investigation of radiosensitive and radioresistant cell populations.

The ARES provides a simple, cost effective exposure platform for conduction research into the effects of exposure of tissue culture to alpha radiation. 


\section{CHAPTER 6. REFERENCES}

[1] Herman Cember, Introduction to Health Physics, 3 ed McGraw-Hill, 1996.

[2] R.B.Firestone, Table of Isotopes, 8 ed. New York: John Wiley \& Sons, Inc., 1996.

[3] "Principles for Limiting Exposure of the Public to Natural Sources of Radiation" Annals of the ICRP, vol. 14, no. 11984.

[4] R.Winkler et al, "Diurnal and seasonal variation of the equilibrium state between short-lived radon decay products and radon gas in groundlevel air" Radiation and Environmental Biophysics, vol. 40, pp. 115-123, Feb.2001.

[5] E.Stranden and L.Berteig, "Radon in dwellings and influencing factors" Health Physics, vol. 39, pp. 275-284, 1980.

[6] D.Krewski et al, "A combined analysis of North American case-control studies of residential radon and lung cancer" Journal of Toxicology and Environmental Health, Part A, vol. 69, pp. 533-597, 2006.

[7] S.Darby et al, "Radon in homes and risk of lung cancer: collaborative analysis of individual data from 13 European case-control studies" BMJ, Feb.2008.

[8] Government of Canada, "Government of Canada Radon Guideline" 2008.

[9] J.Chen et al, "A preliminary radon map for Canada according to health region" Radiation Protection Dosimetry Advance Access, pp. 1-3, 2008.

[10] Federal-Provincial Subcommittee on Drinking Water, "Guidelines for Canadian Drinking Water Quality, 6e" Health Canada, 1996.

[11] I.A.Al-Affan and A.K.Haque, "Local Energy Deposited for Alpha Particles Emitted from Inhaled Radon Daughters" Physics in Medicine and Biology, vol. 34, no. 1, pp. 97-105, 1989.

[12] H.E.Johns and J.R.Cunningham, The Physics of Radiology, 4 ed. Springfield, Illinois: Charles C. Thomas, 1983. 
[13] K.S.Krane, Introductory Nuclear Physics. New York: John Wiley \& Sons, Inc., 1988.

[14] N.N.Das Gupta and S.K.Ghosh, "A report on the Wilson Cloud Chamber and its applications in physics" Reviews of Modern Physics, vol. 18, no. 2, pp. 225-294, 1946.

[15] L.A.Schieve et al, "Evaluation of internal alpha-particle radiation exposure and subsequent fertility among a cohort of women formerly employed in the radium dial industry" Radiation Research, vol. 147, pp. 236-244, 1997.

[16] M.Wickstrom et al, "Relative biological effectiveness (RBE) of ${ }^{210} \mathrm{Po}$ alpha-particles versus x-rays on lethality in bovine endothelial cells" International Journal of Radiation Biology, vol. 79, no. 2, pp. 107-118(12), 2003.

[17] A.Goldfarb and M.Litvinenko, Death of a Dissident: The Poisoning of Alexander Litvinenko and the Return of the KGB, The Free Press, 2007.

[18] E.J.Hall and A.J.Giaccia, Radiobiology for the Radiologist, 6 ed. Philadelphia: Lippincott Williams \& Wilkins, 2006.

[19] E.Stranden, L.Berteig, and F.Ugletveit, "A study on radon in dwellings" Health Physics, vol. 36, pp. 413-421, 1979.

[20] E.J.Hall and T.K.Hei, "Genomic Instability and Bystander Effects Induced by High-LET Radiation" Oncogene, vol. 22, pp. 7034-7042, 2003.

[21] K.L.Andarawewa et al, "Ionizing radiation predisposes nonmalignant human mammary epithelial cells to undergo transforming growth factor b-induced epithelial to mesenchymal transition" Cancer Research, vol. 67, no. 18 , pp. $8662-8670,2007$.

[22] R.I.Freshney, Culture of Animal Cells, 3 ed. New York: Wiley-Liss, 1994.

[23] T.T.Puck et al, "Action of x-rays on mammalian cells. II Survival curves of cells from normal human tissues" J Exp Med, vol. 106, pp. 485-503, 1957. 
[24] T.T.Puck and P.I.Marcus, "Action of x-rays on mammalian cells" $J$ Exp Med, pp. 653-669, 1956.

[25] K.H.Chadwick and H.P.Leenhouts, "A molecular theory of cell survival" Physics in Medicine and Biology, vol. 18, no. 1, pp. 78-87, 1973.

[26] N.Tilly et al, "Comparison of cell survival models for mixed LET radiation" International Journal of Radiation Biology, vol. 75, no. 2, pp. 233$243,1999$.

[27] D.T.Goodhead, J.Thacker, and R.Cox, "Effects of radiations of different qualities on cells: molecular mechanisms of damage and repair" International Journal of Radiation Biology, vol. 63, no. 5, pp. 543-556, Jan.1993.

[28] J.C.Roeske and M.Hoggarth, "Alpha Particle Monte Carlo Simulation for Microdosimetric Calculations Using a Commercial Spreadsheet" Physics in Medicine and Biology, vol. 52, pp. 1909-1922, 2007.

[29] D.Emfietzoglou et al, "Monte Carlo Study of Energy Deposition by Heavy Charged Particles in Sub-Cellular Volumes" Radiation Protection Dosimetry, pp. 1-6, 2007.

[30] S.Incerti et al, "A Comparison of Cellular Irradiation Techniques with Alpha Particles Using the Geant4 Monte Carlo Simulation Toolkit" Radiation Protection Dosimetry, vol. 122, no. 1-4, pp. 327-329, 2007.

[31] S.Incerti et al, "Geant4 simulation of the new CENBG micro and nanoprobes facility" Nuclear Instruments and Methods in Physics Research $B$, vol. 249, pp. 738-742, 2006.

[32] S.Incerti et al, "A comparison of ray-tracing software for the design of quadrupole microbeam systems" Nuclear Instruments and Methods in Physics Research B, vol. 231, pp. 76-85, 2008.

[33] CERN, "Worldwide LHC Computing Grid" http://lcg.web.cern.ch/LCG, 2008.

[34] M.Dressel, "Development in variance reduction techniques" TRIUMF, 2003, pp. 1-20. 
[35] Siegmund Brandt, Data Analysis: Statistical and Computational Methods for Scientists and Engineers Springer-Verlag New York Inc, 1999.

[36] J.F.Ziegler, J.P.Biersack, and M.D.Ziegler, SRIM - The Stopping and Range of Ions in Matter SRIM Co., 2008.

[37] A.A.Dzhurakhalov, S.E.Rahmatov, and H.Dreysse, "Investigation of sputtering and oxygen desoption processes by binary collision approximation method" Computational Materials Science, vol. 33, pp. 250$255,2005$.

[38] S.Agostinelli et al, "Geant4 - a simulation toolkit" Nuclear Instruments and Methods in Physics Research A, vol. 506, pp. 250-303, Jan.2008.

[39] M.Perricone, "Geant4: The physics simulation toolkit" Symmetry, vol. 2, no. 9, pp. 20-23, 2005.

[40] GEANT4 Collaboration, "GEANT4 User's Guide for Application Developers" geant4.9.1 ed 2007, pp. 1-311.

[41] R.Baskar, A.S.Balajee, and C.R.Geard, "Effects of Low and High LET Radiations on Bystander Human Lung Fibroblast Cell Survival" International Journal of Radiation Biology, vol. 83, no. 8, pp. 551-559, 2007.

[42] R.Wang and J.A.Coderre, "A bystander effect in alpha-particle irradiations of human prostate tumor cells" Radiation Research, vol. 164, pp. 711-722, 2005.

[43] A.K.Claesson et al, "Relative biological effectiveness of the alpha-particle emitter 211-At for double-strand break induction in human fibroblasts" Radiation Research, vol. 167, pp. 312-318, 2007.

[44] T.K.Hei et al, "Mutagenic Effects of a Single and an Exact Number of Alpha Particles in Mammalian Cells" Proceedings of the National Academy of Sciences of the United States of America, vol. 94, pp. 3765-3770, 1997.

[45] R.M.Anderson et al, "Effect of linear energy transfer (LET) on the complexity of alpha-particle-induces chromosome aberrations in human CD34+ cells" Radiation Research, vol. 167, pp. 541-550, 2007. 
[46] H.Nagasawa and J.B.Little, "Induction of Sister chromatid Exchanges by Extremely Low Doses of Alpha-Particles" Cancer Research, vol. 52, pp. 6394-6396, 1992.

[47] P.A.Thomas et al, "Relative biological effectiveness (RBE) of 210Po alphaparticles versus X-rays on lethality in bovine endothelial cells" International Journal of Radiation Biology, vol. 79, no. 2, pp. 107-118, 2003.

[48] D.T.Goodhead, "A versatile plutonium-238 irradiator for radiobiological studies with alpha-particles" International Joumal of Radiation Biology, vol. 59, no. 1, pp. 195-210, 1991.

[49] N.Ishigure, T.Nakano, and H.Enomoto, "A Device for In Vitro Irradiation with Alpha-Particles Using an Alpha-Emitting Radioactive Source" Journal of Radiation Research, vol. 32, pp. 404-416, 1991.

[50] H.Roos and A.M.Kellerer, "Design Criteria and Performance Parameteres of an Alpha Irradiation Device for Cell Studies" Physics in Medicine and Biology, vol. 34, no. 12, pp. 1823-1832, 1989.

[51] N.F.Metting et al, "Design of a Benchtop Alpha Particle Irradiator" Health Physics, vol. 68, no. 5, pp. 710-715, 1995.

[52] P.V.S.V.Neti et al, "A Multi-port Low-fluence Alpha-Particle Irradiator: Fabrication, Testing and Benchmark Radiobiological Studies" Radiation Research, vol. 161, pp. 732-738, 2004.

[53] MDS Nordion, "GC40 Fricke Dosimetry Report" 08-0252, 2008.

[54] L.Fengmei et al, "Evaluation of plastic packaging materials used in radiation sterilized medical products and food" Radiation Physics and Chemistry, vol. 57, pp. 435-439, 2000.

[55] J.L.Williams et al, "Radiation stability of polypropylene" Radiation Physics and Chemistry, vol. 9, pp. 445-454, 1977.

[56] NIST, "ASTAR: Stopping-power and range tables for helium ions" 2008.

[57] N.Gault et al, "Biochemical alterations in human cells irradiated with alpha particles delivered by marco- or microbeams" Radiation Research, vol. 167, pp. 551-562, 2007. 
[58] F.James, "A review of pseudorandom number generators" Computer Physics Communications, vol. 60, pp. 329-344, 1990.

[59] I. P. Eckert \& Ziegler, "Radiation Source Handling Instructions for Reference and Calibration Sources" 2008.

[60] T.Elsdale and J.Bard, "Collagen Substrata for Studies on Cell Behaviour" The Journal of Cell Biology, vol. 54, pp. 626-637, 1972.

[61] J.H.Lillie, D.K.MacCallum, and A.Jepsen, "Fine Structure of Subcultivated Stratified Squamous Epithelium Grown on Collagen Rafts," Experimental Cell Research, vol. 125, pp. 153-165, 1980.

[62] T.Aoki et al, "Molecular dynamics and Monte-Carlo simulation of sputtering and mixing by ion irradiation" Nuclear Instruments and Methods in Physics Research B, vol. 180, pp. 312-316, 2001.

[63] B.E.Leonard, "A composite microdose Adaptive Response (AR) and Bystander Effect (BE) model - application to low LET and high LET AR and BE data" International Journal of Radiation Biology, vol. 84, no. 8, pp. 681-701, 2008. 


\section{APPENDIX A}

\section{Sample Calculations}

Change in Activity

$$
1-\frac{A}{A_{o}}=e^{-\ln 2 \cdot t / t_{1}}
$$

Example: ${ }^{137} \mathrm{Cs}$

Half-life $\left(\mathrm{t}_{\frac{1}{2}}\right)=30.23$ years

Period of time $(t)=30$ days or 0.082 years

Change in activity $=0.19 \%$

Fraction of attenuation calculations for various materials

$$
1-\frac{I}{I_{0}}=(E) e^{-\mu(E) x}
$$

Example: Polystyrene

Thickness $(x)=0.1 \mathrm{~cm}$

$\mathrm{E}=662 \mathrm{keV}$

$\mu(E)=0.086652 \mathrm{~cm}^{-1}$

Fraction of attenuation $=0.01$

Stopping Range data calculations for various materials

$$
\text { Range }(\mathrm{cm})=\frac{C S D A \text { Range }\left(\mathrm{g} \cdot \mathrm{cm}^{-2}\right)}{\text { Density }\left(\mathrm{g} \cdot \mathrm{cm}^{-3}\right)}
$$

Example: Air

Density $=1.205 \times 10^{-3} \mathrm{~g} \mathrm{~cm}^{-3}$

CSDA Range $=5.020 \times 10^{-3} \mathrm{~g} \mathrm{~cm}^{-2}$

Range $=4.166 \mathrm{~cm}$ 